\title{
CD8+ T Lymphocyte Epitopes From The Herpes Simplex Virus Type 2 ICP27, VP22 and VP13/14 Proteins To Facilitate Vaccine Design And Characterization
}

\author{
Rebecca J. Platt ${ }^{1}$, Tansi Khodai ${ }^{2}$, Tim J. Townend ${ }^{1}$, Helen H. Bright ${ }^{2}$, Paul Cockle ${ }^{3}$, \\ Luis Perez-Tosar ${ }^{1}$, Rob Webster ${ }^{1}$, Brian Champion ${ }^{3}$, Timothy P. Hickling ${ }^{1, *, \dagger}$ and Fareed Mirza ${ }^{1}$ \\ 1 Biotherapeutics and Translational Research, Pharmacokinetics, Dynamics \& Metabolism, \\ Pfizer Global Research and Development, Sandwich, Kent, CT13-9NJ, UK; \\ E-Mails: Rebecca.Platt@Covance.com (R.J.P.); tim.j.townend@gsk.com (T.J.T.); \\ Luis.Perez@ablynx.com (L.P-T.); rob.webster@pfizer.com (R.W.); fareed.mirza@novartis.com (F.M.) \\ 2 New Opportunities Unit, Pfizer Global Research and Development, Sandwich, Kent, CT13 -9NJ, \\ UK; E-Mails: tansi.khodai@googlemail.com (T.K.); h.h.bright@btinternet.com (H.H.B.) \\ 3 Vaccine Research Unit, Pfizer Global Research and Development, Sandwich, Kent, CT13-9NJ, \\ UK; E-Mails: paul.cockle@pfizer.com (P.C.); brian.champion@pfizer.com (B.C.) \\ $\dagger$ Present address: Biotherapeutics and Translational Research, Pharmacokinetics, \\ Dynamics \& Metabolism, Pfizer Inc, One Burtt Road, Andover, MA 01810, USA. \\ * Author to whom correspondence should be addressed; E-Mail: timothy.hickling@pfizer.com; \\ Tel.: +1-978-247-2909.
}

Received: 19 October 2012; in revised form: 22 November 2012 / Accepted: 27 December 2012 / Published: 4 January 2013

\begin{abstract}
CD8 + T cells have the potential to control HSV-2 infection. However, limited information has been available on $\mathrm{CD} 8+\mathrm{T}$ cell epitopes or the functionality of antigen specific $\mathrm{T}$ cells during infection or following immunization with experimental vaccines. Peptide panels from HSV-2 proteins ICP27, VP22 and VP13/14 were selected from in silico predictions of binding to human HLA-A*0201 and mouse H-2Kd, Ld and Dd molecules. Nine previously uncharacterized CD8 $+\mathrm{T}$ cell epitopes were identified from HSV-2 infected BALB/c mice. HSV-2 specific peptide sequences stabilized HLA-A*02 surface expression with intermediate or high affinity binding. Peptide specific CD8+ human $\mathrm{T}$ cell lines from peripheral blood lymphocytes were generated from a HLA-A*02+ donor. High frequencies of peptide specific CD8+ T cell responses were elicited in mice by DNA vaccination with ICP27, VP22 and VP13/14, as demonstrated by CD107a
\end{abstract}


mobilization. Vaccine driven $\mathrm{T}$ cell responses displayed a more focused immune response than those induced by viral infection. Furthermore, vaccination with ICP27 reduced viral shedding and reduced the clinical impact of disease. In conclusion, this study describes novel HSV-2 epitopes eliciting strong CD8 $+\mathrm{T}$ cell responses that may facilitate epitope based vaccine design and aid immunomonitoring of antigen specific $\mathrm{T}$ cell frequencies in preclinical and clinical settings.

Keywords: HSV-2; CD8+ epitope; vaccine; infection

\section{Introduction}

Herpes Simplex Virus Type 2 (HSV-2) is responsible for recurrent genital ulcers, cold sores, herpetic stromal keratitis and fatal encephalitis, and contributes to morbidity seen in immunocompromised individuals and neonates with severe infection. HSV-2 is a major global health concern with an estimated 123 million people infected in Sub-Saharan Africa (15-49 years) compared with 29.8 million in the US and 20.9 million in Europe [1,2]. Long term treatment of HSV-2 infection with anti-viral drugs has been successful in managing the disease by reducing recurrent activation, limiting viral shedding and reducing transmission of the virus. Although therapeutic treatments are widely available, development of a prophylactic vaccine to achieve sterilizing immunity is highly desirable. Two clinical vaccine studies aimed at generating neutralizing antibodies and CD4+ T cell responses have resulted in limited success. The former prophylactic vaccine delivered HSV-2 glycoproteins ( $\mathrm{gD}$ and $\mathrm{gB}$ ) in combination with the adjuvant MF59 and generated neutralizing antibodies but demonstrated transient efficacy in only a minor cohort of individuals [3,4]. Another prophylactic approach used the HSV-2 glycoprotein-D-subunit vaccine with alum and 3-O-deacylatedmonophosphoryl lipid A (MPL) though efficacy was only observed in HSV-1 and HSV-2 seronegative females [5,6].

Vaccine strategies aimed at generating $\mathrm{CD} 8+\mathrm{T}$ cell responses and targeting additional immunogenic HSV-2 proteins have potential to result in better efficacy [7-9]. Increased knowledge of CD8+ T cell epitope sequences will aid vaccine design by the incorporation of immunogenic peptide sequences into vaccines and allow detailed phenotypic analysis and characterization of the kinetics of the cellular immune response after immunization. The underlying mechanistic T cell control of HSV-2 is not well understood, however emerging data has highlighted the importance of CD8+ T cell control in HSV-2 reactivation and for maintaining but not establishing latency [10,11]. Zhu et al. have shown that CD8+ T cells have a key role in the control and progression of HSV-2 by localizing at the site of infection [12]. Adoptive transfer experiments using OVA specific CD8+ T cells in HSV-2 Tk-OVA infected mice resulted in clearance of infection that could be reversed by the in vivo neutralization of IFN-Y [13]. Interestingly, the protein ICP4 has recently been shown to be the target of granzyme B mediated degradation, which results in non lethal viral inactivation [14]. CD8+ T cells were shown to control viral reactivation in cultured trigeminal ganglia (TG) from HSV-2 infected mice. Depleting CD8 $+\mathrm{T}$ cells from cultures promoted increased rates of HSV-2 reactivation [15]. Clinical studies evaluating the diversity of CD8+ restricted T cell responses to HSV-2 proteins have shown that the 
greatest frequency of responses are directed against tegument proteins but are only found in $50 \%$ of patients [16] and that CD4+ responses are broader than CD8+ [17]. The CD8+, IFN- $++\mathrm{T}$ cell responses were restricted to the VP22, ICP0 and ICP4 antigens with no additional responses detected ex vivo for ICP27, ICP22 or $\mathrm{gD}$ proteins. These important findings indicate that tegument protein specific $\mathrm{T}$ cells may play an important role in controlling HSV-2 infection and provide attractive opportunities for immune intervention.

ICP27, VP22 and VP13/14 have previously been shown to elicit strong T cell responses in mice and have been used for exploratory vaccine studies [18-21]. With limited epitope information available on ICP27, VP22 and VP13/14 we sought to identify epitope sequences in a preclinical BALB/c mouse model using a combination of computational prediction, ELISpot and flow cytometry methods. Responses to VP22 and VP13/14 have also been demonstrated in humans [22]. Translational studies using HLA-A*02-peptide binding assays and human $\mathrm{T}$ cell lines generated by peptide driven expansions from well conserved ICP27, VP22, and VP13/14 epitope sequences exhibited functional activity in response to their cognate peptide stimulation in vitro. In order to induce CD8+ T cell responses to HSV-2 proteins through active immunization, we constructed DNA vaccines encoding full length ICP27, VP22, and VP13/14 proteins. To facilitate strong MHC class I mediated expression of viral proteins, DNA was delivered using the proprietary gold particle mediated epidermal delivery $\left(\mathrm{PMED}^{\mathrm{TM}}\right)$ with the ND10 delivery device [23]. CD8+ T cell responses were evaluated using ELISpot and mobilization of CD107a after peptide stimulation. Epitope specific $\mathrm{T}$ cell responses generated from PMED DNA immunization showed a narrowed and more focused T cell response towards ICP27, VP22 and VP13/14 as compared with HSV-2 infection in BALB/c mice. These T cell epitopes may facilitate vaccine design and aid immunomonitoring of peptide specific $\mathrm{T}$ cell responses in pre-clinical and clinical studies.

\section{Results and Discussion}

\subsection{Identification of Epitopes in ICP27, VP22 and VP13/14}

Computer aided epitope identification has proven to be a very powerful tool to select specific areas within large protein sequences with immunogenic potential. To aid the identification of CD8+ restricted $\mathrm{T}$ cell epitopes we used linear based epitope detection methods, including ELISpot, to narrow $15 \mathrm{mer}$ peptide specific responses to 9mer peptides for in vitro $\mathrm{T}$ cell stimulation experiments using BALB/c mice infected with HSV-2. The peptides derived from ICP27, VP22 and VP13/14 were identified based on the ability to bind $\mathrm{Kd}, \mathrm{Dd}, \mathrm{Ld}$ and HLA-A*02 MHC molecules using the Immune Epitope Database [24] (Table 1). The sequence from ICP27 (318-326) has previously been shown to elicit strong $\mathrm{T}$ cell responses in preclinical experiments and was included as a positive control [18]. Additionally the Flu matrix $\mathrm{M}_{(58-66)}$ epitope served as positive control for the bioinformatics screening and for T2 stabilization studies. 
Table 1. Sequence information and predicted IC50 (nM) binding values for ICP27, VP22 and VP13/14 selected peptides.

\begin{tabular}{|c|c|c|c|c|c|}
\hline Epitope & $\begin{array}{c}\text { Peptide } \\
\text { Sequence }\end{array}$ & $\begin{array}{c}\text { Predicted }{ }^{\text {a }} \text { IC50 } \\
\text { (nM) for Kd }\end{array}$ & $\begin{array}{c}\text { Predicted }{ }^{\text {a }} \text { IC50 } \\
(\mathrm{nM}) \text { for Dd }\end{array}$ & $\begin{array}{c}\text { Predicted }^{\text {a }} \text { IC50 } \\
\text { (nM) for Ld }\end{array}$ & $\begin{array}{l}\text { Predicted }{ }^{\text {a }} \text { IC50 } \\
\text { (nM) for HLA-A2 }\end{array}$ \\
\hline ICP27(314-322) & TLVAHGPSL & 29704.2 & 29811.3 & 29903.8 & 172.1 \\
\hline ICP27(318-326) * & HGPSLYRTF * & 29523.2 & 41.4 & 26435.4 & 24491.7 \\
\hline ICP27(319-327) & GPSLYRTFA & 37218.7 & 32191.1 & 36928.3 & 24083.7 \\
\hline $\mathrm{ICP} 27(424-432)$ & DIASFVLVI & 32248.6 & 16323.4 & 44299.6 & 12567.5 \\
\hline ICP27(425-433) & IASFVLVIL & 27247.8 & 29428.1 & 38689.5 & 5961 \\
\hline ICP27(427-435) & SFVLVILAR & 31071.1 & 33613.3 & 45487.2 & 23983 \\
\hline ICP27(428-436) & FVLVILARL & 15291.9 & 31066.4 & 39404.5 & 44.2 \\
\hline ICP27(459-467) & TMHFYIPGA & 39602.4 & 29117.4 & 44287.4 & 37.3 \\
\hline ICP27(462-470) & FYIPGACMA & 2073.3 & 30525.3 & 43726.8 & 13482.9 \\
\hline ICP27(464-472) & IPGACMAGL & 22701.7 & 8136.7 & 322.7 & 21245.3 \\
\hline ICP27(479-487) & HRQECSSRV & 32214.5 & 31069.2 & 39806.7 & 19930.4 \\
\hline ICP27(482-490) & ECSSRVCEL & 31674.4 & 23031 & 43090.6 & 22306.7 \\
\hline ICP27(484-492) & SSRVCELTA & 37431.5 & 29921.3 & 44401.6 & 23541.2 \\
\hline ICP27(499-507) & LYVHGKYFY & 31170.9 & 31676 & 42144.7 & 24253.4 \\
\hline ICP27(500-508) & YVHGKYFYC & 39488.8 & 31902.1 & 31410.8 & 4141.3 \\
\hline $\mathrm{ICP} 27(502-510)$ & HGKYFYCNS & 39256 & 30676.7 & 44620 & 24494 \\
\hline $\mathrm{ICP} 27(504-512)$ & KYFYCNSLF & 1731.1 & 19533.6 & 35494.7 & 22076.5 \\
\hline VP22(46-54) & MRARPRGEV & 33458 & 31986.6 & 40180.1 & 22734.7 \\
\hline VP22(49-57) & RPRGEVRFL & 35468.7 & 32591.2 & 15593.8 & 24194.2 \\
\hline VP22(144-152) & PAQADSAVL & 31273.4 & 27008 & 39887.1 & 22567.6 \\
\hline VP22(146-154) & AQADSAVLL & 28650.2 & 29610.5 & 39773.3 & 219.8 \\
\hline VP22(170-178) & QGLAKKLHF & 36005.8 & 25105.8 & 28660.9 & 24422.6 \\
\hline VP22(171-179) & GLAKKLHFS & 38907.3 & 30342.7 & 44645.9 & 3066.5 \\
\hline VP22(172-180) & LAKKLHFST & 36466.3 & 32481.7 & 41828.9 & 22976.2 \\
\hline VP22(173-181) & AKKLHFSTA & 36250.5 & 33000.5 & 44582.4 & 24606.2 \\
\hline VP22(197-205) & NKRVFCAAV & 30008.2 & 31775.2 & 44919.6 & 22655.2 \\
\hline VP22(200-208) & VFCAAVGRL & 1306.3 & 32999.6 & 9018.9 & 21578.2 \\
\hline VP13/14(224-232) & FYPCPDSAF & 16119.3 & 1274.8 & 39803 & 24361.5 \\
\hline VP13/14(225-233) & YPCPDSAFG & 39192.9 & 34274.1 & 34907.2 & 24514.4 \\
\hline VP13/14(228-236) & PDSAFGLSR & 39770.5 & 33330.2 & 45411.5 & 24833.9 \\
\hline VP13/14(229-237) & DSAFGLSRV & 31063.7 & 29721.2 & 44388.9 & 21332.2 \\
\hline VP13/14(242-250) & FASPADPKV & 36540 & 26313.6 & 7025.5 & 743 \\
\hline VP13/14(243-251) & ASPADPKVF & 37288.4 & 6838.7 & 31207.7 & 24557.9 \\
\hline VP13/14(244-252) & SPADPKVFF & 37123.2 & 13334.2 & 232.3 & 24985.9 \\
\hline VP13/14(394-402) & TYIATGALL & 21.5 & 25985.1 & 34758.1 & 19830.3 \\
\hline VP13/14(395-403) & YIATGALLA & 37750 & 31700.8 & 44153.7 & 162.8 \\
\hline VP13/14(414-422) & LPREAAFAG & 39383.4 & 33334.8 & 26281.3 & 24771.1 \\
\hline VP13/14(415-423) & PREAAFAGR & 39228.2 & 32630.7 & 43207.1 & 24858.4 \\
\hline VP13/14(419-427) & AFAGRVLDV & 25977.5 & 20910.7 & 40665.1 & 11777.1 \\
\hline VP13/14(421-429) & AGRMTYIAT & 36221.7 & 30484.7 & 44486.5 & 24623 \\
\hline
\end{tabular}


Table 1. Cont.

\begin{tabular}{cccccc}
\hline Epitope & $\begin{array}{c}\text { Peptide } \\
\text { Sequence }\end{array}$ & $\begin{array}{c}\text { Predicted } \\
\text { (nM) for } \text { Kd }\end{array}$ & $\begin{array}{c}\text { Predicted }^{\text {a }} \text { IC50 } \\
(\mathbf{n M}) \text { for Dd }\end{array}$ & $\begin{array}{c}\text { Predicted }^{\text {a }} \text { IC50 } \\
(\mathbf{n M )} \text { for Ld }\end{array}$ & $\begin{array}{c}\text { Predicted }{ }^{\text {a }} \text { IC50 } \\
\text { (nM) for HLA-A2 }\end{array}$ \\
\hline VP13/14(589-597) & TQPLYARTT & 39452.7 & 25084.5 & 45112 & 22116.8 \\
VP13/14(590-598) & QPLYARTTP & 28489.2 & 31596.9 & 30047.2 & 24585.7 \\
VP13/14(591-599) & PLYARTTPA & 28610.6 & 28076.8 & 44528.9 & 2426.4 \\
VP13/14(592-600) & LYARTTPAK & 23103.7 & 30223.7 & 45027.4 & 24767.2 \\
\hline
\end{tabular}

* Denotes a previously described epitope in BALB/c mice (see reference [18]); ${ }^{a}$ Predictions were performed using IEDB www.immuneepitope.org (see reference [24] and methods); ${ }^{b}$ Known HLA-A2 binder.

\subsection{Identification of Epitopes in ICP27, VP22 and VP13/14 from HSV-2 Infected BALB/c Mice}

HSV-2 infection studies in BALB/c mice were performed to identify strong peptide specific $\mathrm{T}$ cell responses. BALB/c mice were infected with HSV-2 and monitored for 14 days before spleens were removed and harvested for splenocytes. IFN- $\gamma$ ELISpots were used to measure $\mathrm{T}$ cell responses after overnight stimulation with peptide. Intra-vaginal infection of mice with HSV-2 strain 333 resulted in a broad detectable cellular immune response towards ICP27, VP22 and VP13/14 (Figure 1 A,B,C and Table 2). The previously reported mouse epitope ICP27 $7_{(318-326)}$ elicited a strong response after infection $(n=4)$ as expected. Peptide sequences that have not been previously described for ICP2 $7_{(500-508) \text {, }}$

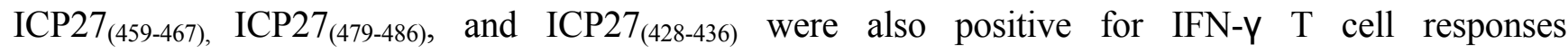
( $\geq 90 \mathrm{SFC} /$ million splenocytes) after peptide stimulation. Interestingly, overlapping amino acid sequences from ICP27 $7_{(314-322)}$ and ICP27 $7_{(319-327)}$ gave lower responses than ICP2 $7_{(318-326)}$ (Figure 1A). Strong peptide specific responses were seen with $\mathrm{ICP}_{2} 7_{(462-470)}$ and $\mathrm{ICP}_{2} 7_{(500-508)}$ which were comparable to the published sequence ICP27 $7_{(318-326)}$ (Figure 1A). Further epitope screening of VP22 and VP13/14 peptides resulted in three strongly positive epitopes being identified (VP22 $2_{(46-54),}$ VP22(171-179) and VP22 $2_{(200-208)}$ ) and two from VP13/14 (VP13/14 ${ }_{(244-252)}$ and VP13/14 $\left.{ }_{(592-600)}\right)$ shown in Figure 1B and Figure 1C. Splenocytes pulsed with individual peptides from naive mice $(\mathrm{n}=2)$ gave background responses below 16.5 SFC per million splenocytes (Table 2). Although identification of potential epitopes in mice is highly informative, further work is required to assess the involvement of $\mathrm{T}$ cell subsets that are able to induce IFN- $\gamma$ production. We have made use of peptides that span 9 amino acids which have a natural affinity for MHC class I molecules, however it has been shown that the MHC class II molecule requires a 9mer sequence to obtain core binding $[25,26]$. To exclude the possibility of CD4+ mediated IFN- $\gamma$ responses after infection with $\mathrm{HSV}-2$, cells sorted for CD4+ and CD8 $+\mathrm{T}$ cells may be used in peptide pulsing studies. Additionally, measurement of total IFN- $\gamma$ positive responses to whole virus, protein or a full set of overlapping peptides spanning the full length of viral antigens would allow ranking of the magnitude of peptide specific responses. From the predicted IC50 binding values it is apparent which $\mathrm{BALB} / \mathrm{c}$ allele each peptide is restricted to, however experimental validation using cell lines expressing $\mathrm{H} 2$ molecules are required for detailed pre-clinical MHC-peptide tetrameric and phenotypic analysis of peptide specific $\mathrm{T}$ cells are required. The identification of epitopes in HSV-2 viral proteins were identified in an infection setting with a virus presenting multiple $\mathrm{H} 2$ restricted $\mathrm{T}$ cell epitopes from different proteins. To translate our findings with clinical significance it is necessary to determine human HLA-A*02 restricted epitopes in HSV-2 proteins. 
Figure 1. Identification of epitopes in ICP27, VP22 and VP13/14 from HSV-2 infected $\mathrm{BALB} / \mathrm{c}$ mice. BALB/c mice were infected with $1 \times 10^{3}$ pfu of HSV-2 (strain 333) through intra-vaginal administration. After 14 days splenocytes were obtained and pulsed individually $\left(5 \times 10^{5}\right.$ cells) with $10 \mu \mathrm{g} / \mathrm{mL}$ of (A) ICP27, (B) VP22 and (C) VP13/14 derived peptides in an overnight IFN- $\gamma$ ELISPpot assay. Counts are presented as spot forming cells per million splenocytes with standard error of means (SEM). Cut off values 2 SD over background were considered significant and spots reaching 90 SFU or above were defined as positive.

ICP27 epitope mapping in splenocytes from HSV-2 infected Balb/c mice

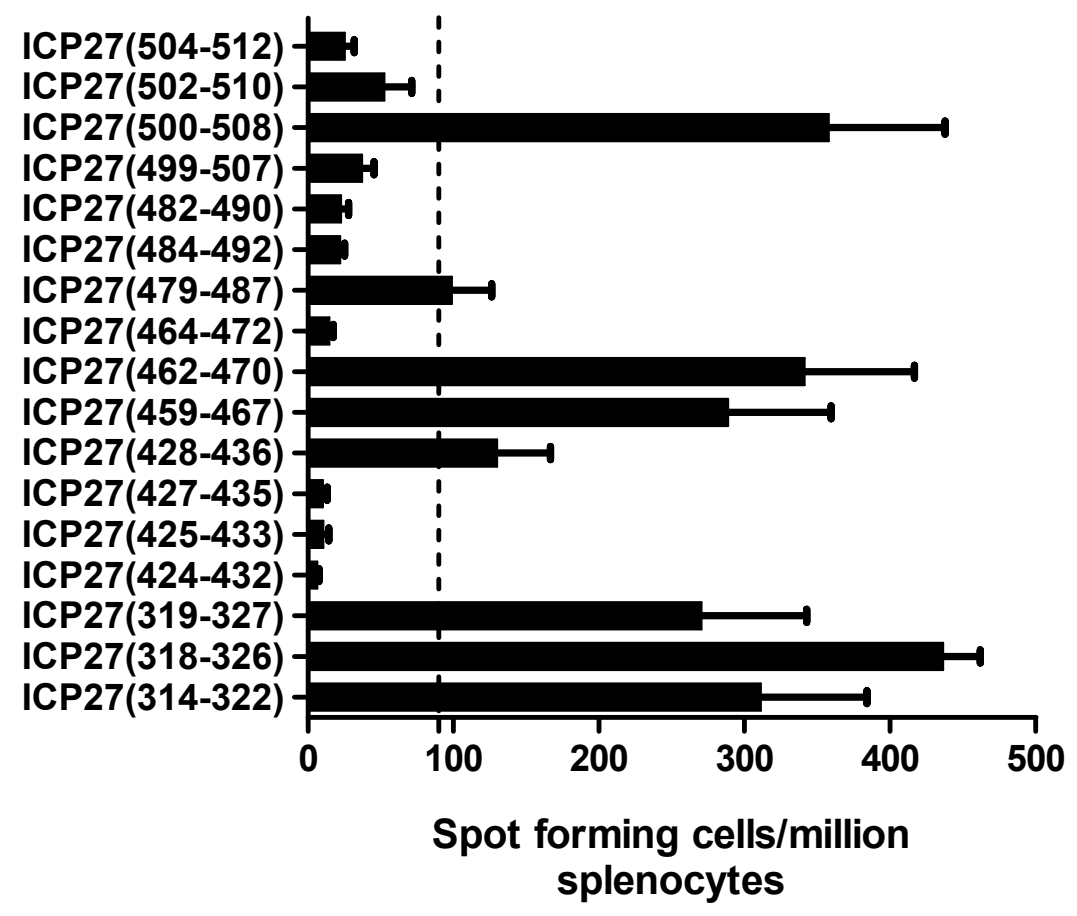

(A)

VP22 epitope mapping in splenocytes from HSV-2 infected Balb/c mice

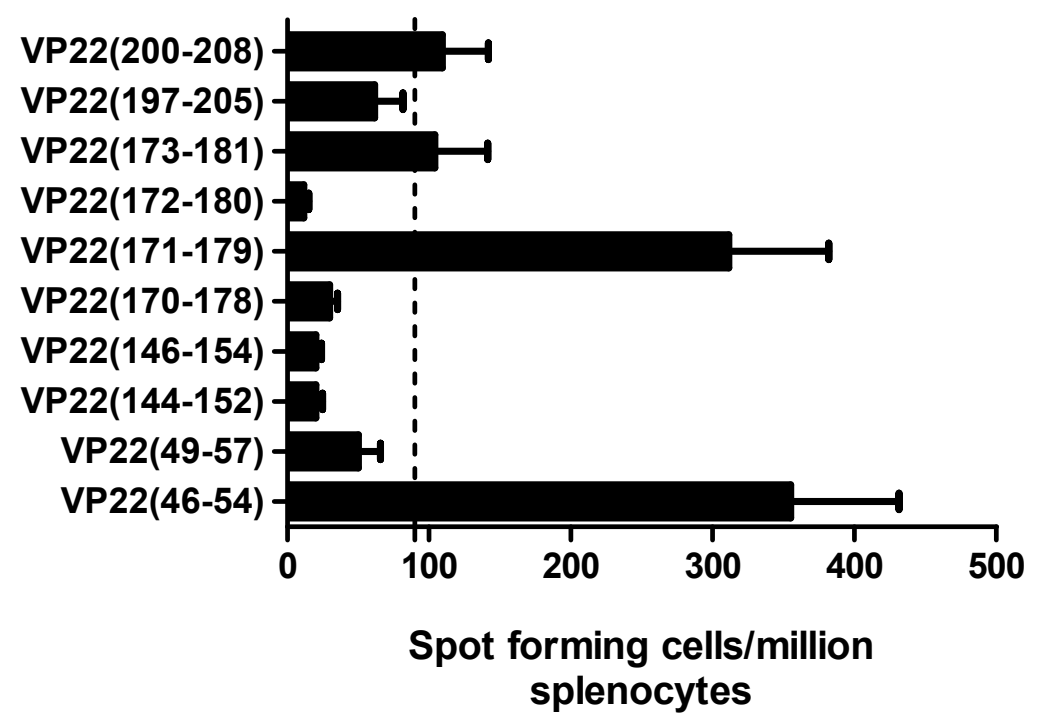

(B) splenocytes 
Figure 1. Cont.

\section{VP13/14 epitope mapping in splenocytes from HSV-2 infected Balb/c mice}

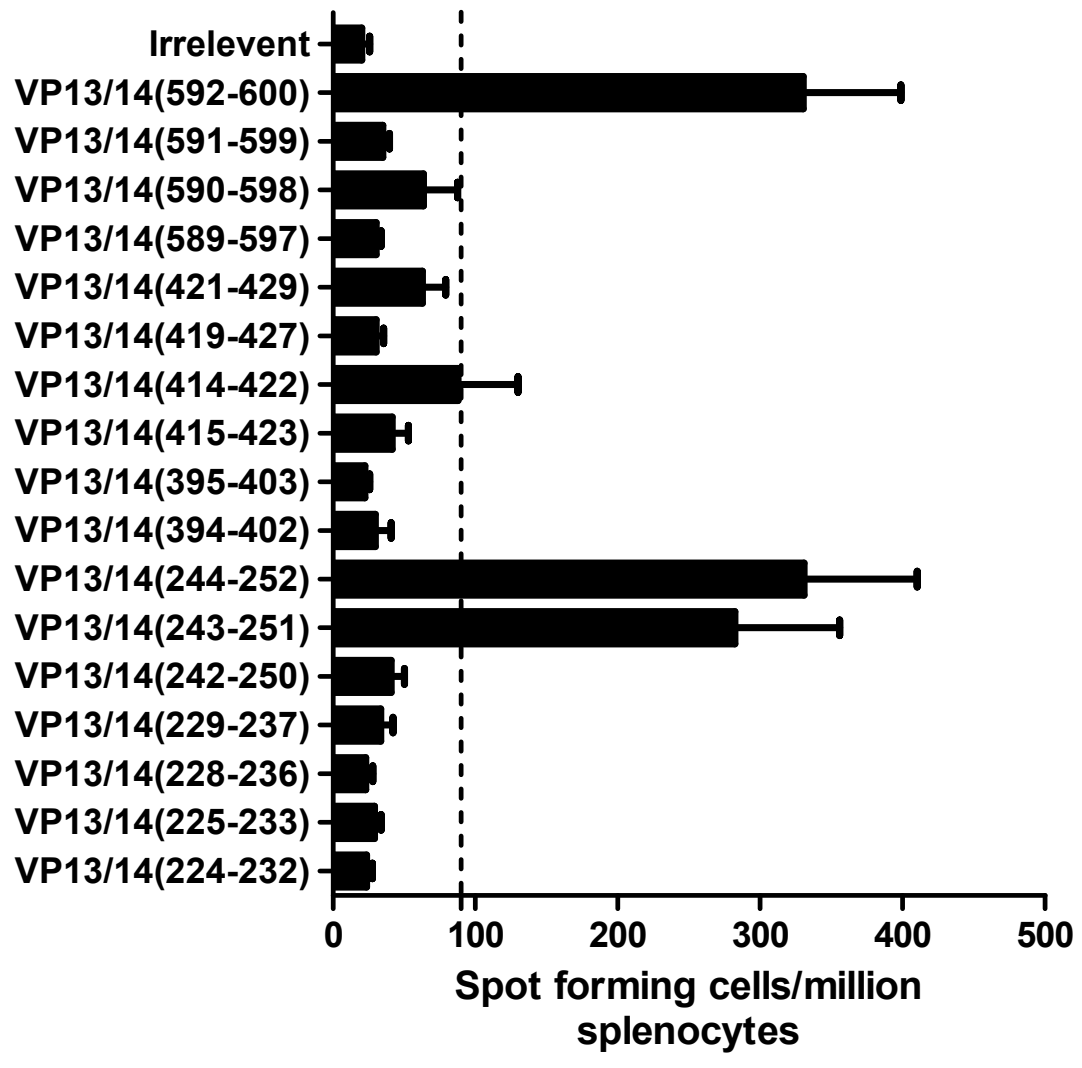

Table 2. Summary of epitopes identified from HSV-2 proteins in BALB/c mice after infection and immunization with ICP27, VP22 and VP13/14 DNA vaccines.

\begin{tabular}{|l|l|c|c|c|}
\hline BALB/c Epitope & \multicolumn{1}{|c|}{$\begin{array}{c}\text { Peptide } \\
\text { Sequence }\end{array}$} & $\begin{array}{c}\text { IFN- } \boldsymbol{\gamma} \text { Responses (SFC) } \\
\text { after HSV-2 Infection in } \\
\text { BALB/c mice (n=4) }\end{array}$ & $\begin{array}{c}\text { IFN- } \boldsymbol{\gamma} \text { Responses (SFC) in } \\
\text { Mice Immunized with Full } \\
\text { Length DNA Vaccine (n= 6) }\end{array}$ & $\begin{array}{c}\text { IFN- } \boldsymbol{\gamma} \text { Responses } \\
\text { (SFC) in Uninfected } \\
\text { BALB/c Mice (n= 2) }\end{array}$ \\
\hline ICP27(318-326) * & HGPSLYRTF & 436.2 & 304.4 & 16.5 \\
\hline ICP27(428-436) & FVLVILARL & 129.7 & 71 & 7.5 \\
\hline ICP27(459-467) & TMHFYIPGA & 288.5 & 12.5 & 5.5 \\
\hline ICP27(479-487) & HRQECSSRV & 98.75 & 247 & 5.5 \\
\hline ICP27(500-508) & YVHGKYFYC & 357.7 & 4.5 & 4.5 \\
\hline VP22(46-54) & MRARPRGEV & 354.7 & 23.8 & 3 \\
\hline VP22(171-179) & GLAKKLHFS & 311.2 & 189.6 & 8 \\
\hline VP22(200-208) & VFCAAVGRL & 109.2 & ND ** & 9.5 \\
\hline VP13/14(244-252) & SPADPKVFF & 330.7 & ND ** & 4.5 \\
\hline VP13/14(592-600) & LYARTTPAK & 330 & & 8.5 \\
\hline
\end{tabular}

* Denotes a previously described epitope in BALB/c mice (see reference [18]); ${ }^{\psi}$ Mice immunized with DNA vaccine encoding ICP27, VP22 or VP13/14 using PMED device. Naïve mice immunized with DNA encoding mock antigen showed mean background responses for individual peptides less than 5 SFU/million splenocytes $(\mathrm{n}=6)^{\prime} * *$ ND (Not determined). 


\subsection{Determination of HLA-A*02 Restricted $H S V$-2 Epitopes}

Epitope predictions highlighted the potential for peptide binding to the MHC class 1 molecule with high affinity (affinity index $\geq 1.5$ ) in comparison to the Flu Matrix M1 epitope [27]. T2 cells were used to determine the affinity index of peptides able to bind and stabilize HLA-A*02 MHC molecules. Figure 2A shows the AI for all 44 peptides calculated from mean fluorescent intensities. Four peptide sequences, ICP27 $7_{(314-322)}, \mathrm{VP} 22_{(146-154)}, \mathrm{VP} 22_{(173-181)}, \mathrm{VP} 13 / 14_{(242-250)}$ were able to reach an AI $>1.5$ (high affinity) and ICP27(428-436) scored 1.42 (intermediate affinity) (Figure 2A). Figure 2B shows shift in intensity of HLA-A*02 on T2 cells for the strongest ICP27, VP22 and VP13/14 peptide binders. The human donors had no history of HSV-2 infection, but are likely to have been exposed to HSV-1. Alignment of the HLA-A*02 restricted peptides identified for HSV-2 with the sequences for HSV-1 ICP27, VP22 and VP13/14 proteins showed close homology for three out of four peptides. Although samples from our donors required repetitive in vitro re-stimulation in order to identify specific responses, there have been reports demonstrating HSV-2 specific $\mathrm{T}$ cells in seronegative individuals [28] which is similar to T cells found in HIV-1 exposed but uninfected individuals [29-31].

Figure 2. HLA-A2 stabilization by exogenously loaded peptides on T2 cells. T2 cells were plated out in a 96 well plate. Peptide $(50 \mu \mathrm{g} / \mathrm{mL})$ was added and the cells were left to incubate overnight. (A) Stabilized expression of HLA-A2 was detected using a FITC conjugated BB7.2 antibody. The HLA-A2 restricted Flu matrix M1 ${ }_{(58-66)}$ (GILGFVFTL) peptide was used as positive control at the same concentration as the HSV-2 test peptides (shown in red). (B) Relative peptide binding affinity was calculated from the formula: $\mathrm{AI}=\left(\mathrm{MFI}_{1}-\mathrm{MFI}_{0}\right) /\left(\mathrm{MFI}_{2}-\mathrm{MFI}_{0}\right)$ (see methods). The dashed line represents an $\mathrm{AI}$ of $\leq 1.5$ (high affinity) and the dotted line represents an AI of $\geq 1.25$ (intermediate affinity).

(i) FITC Isotype control, (ii) Irrelevant control, (iii) Unpulsed cells, (iv) Influenza matrix (58-66),

(v) ICP27 (314-322), (vi) ICP27 $_{(428-436)}$, (vii) VP22 (146-154), (viii) VP22 (173-181), (ix) VP13/14 (242-252)

Peptide affinity index for HLA-A2 stabilization on T2 cells

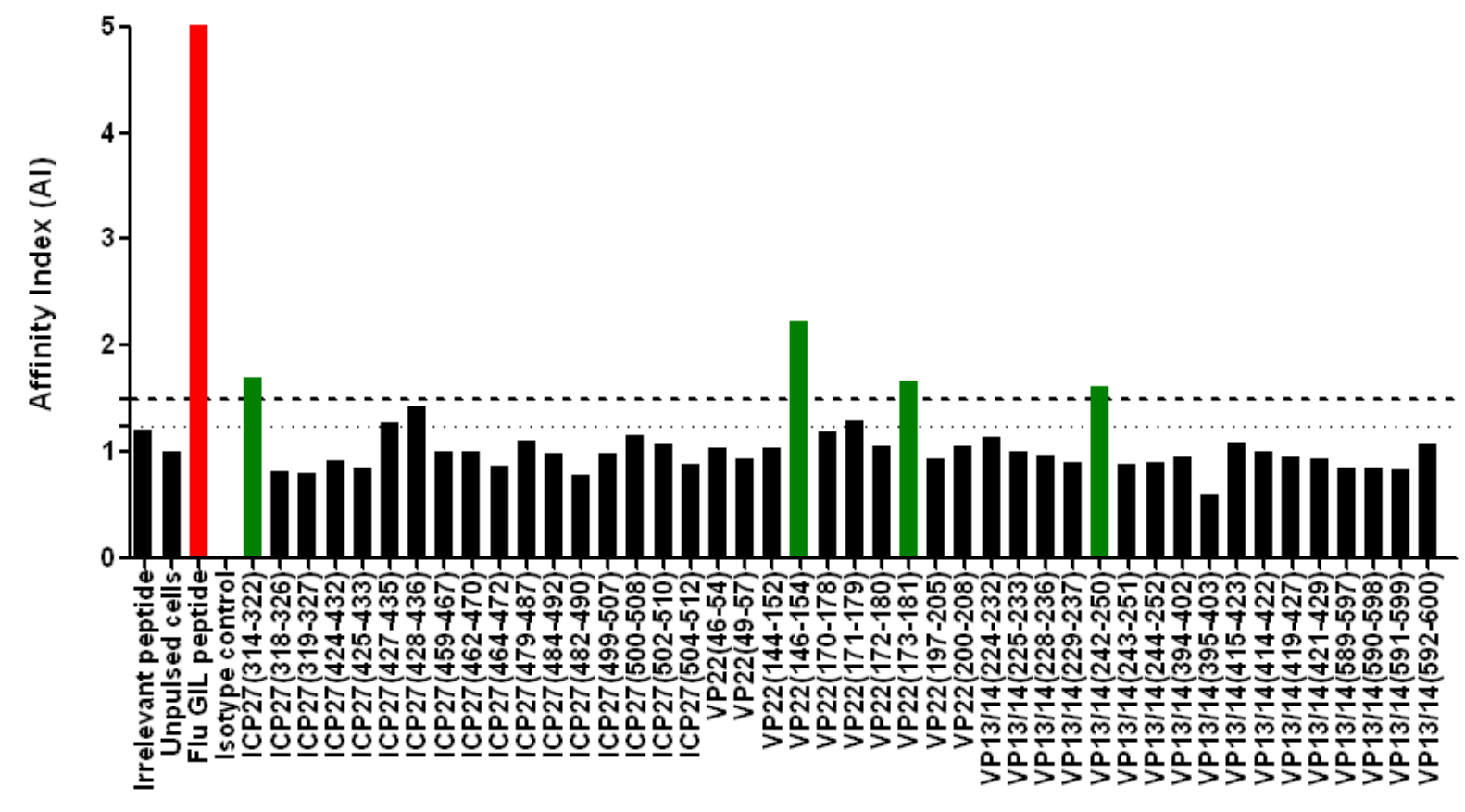


Figure 2. Cont.

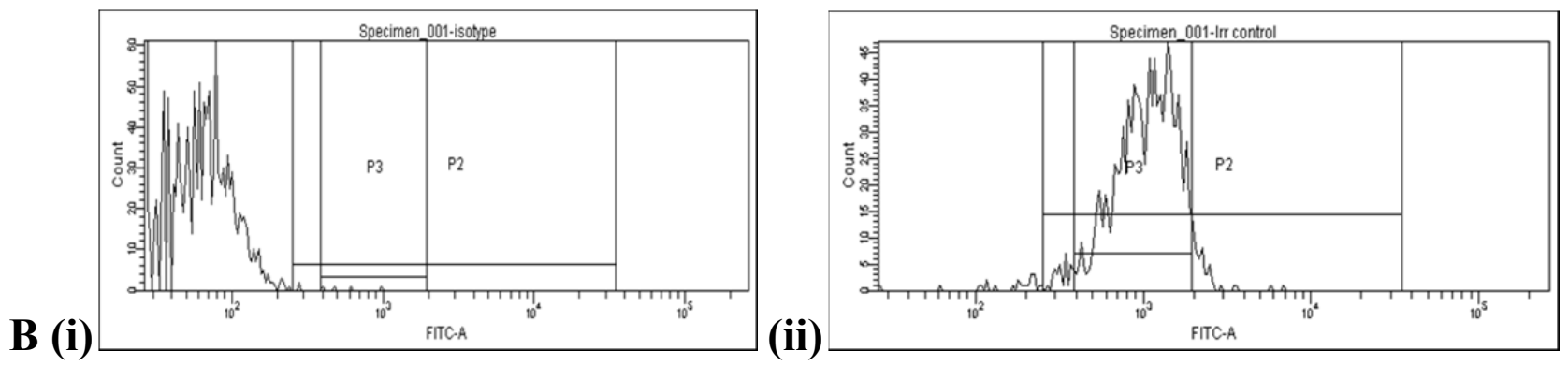

(iii)
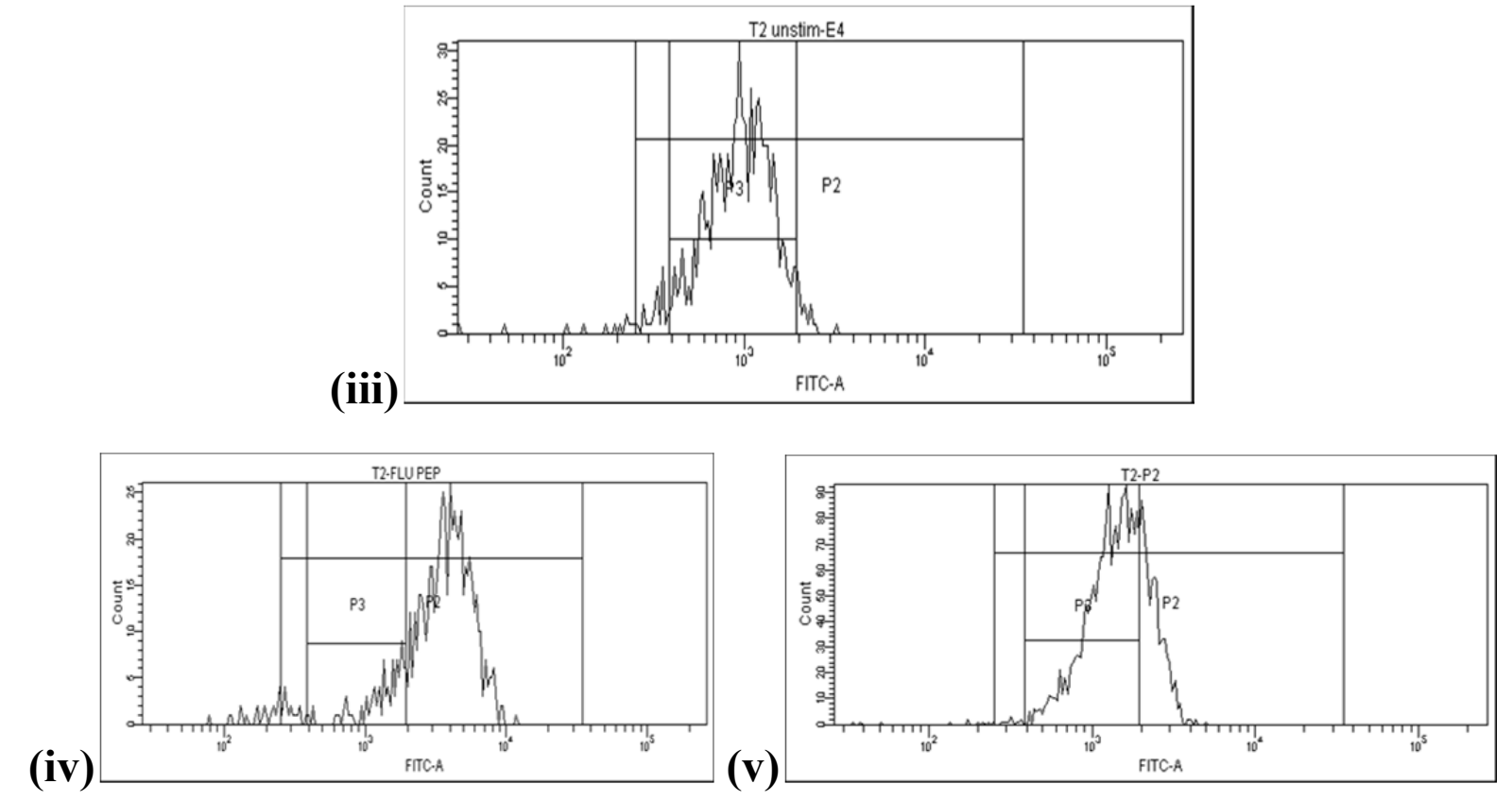

(vi)
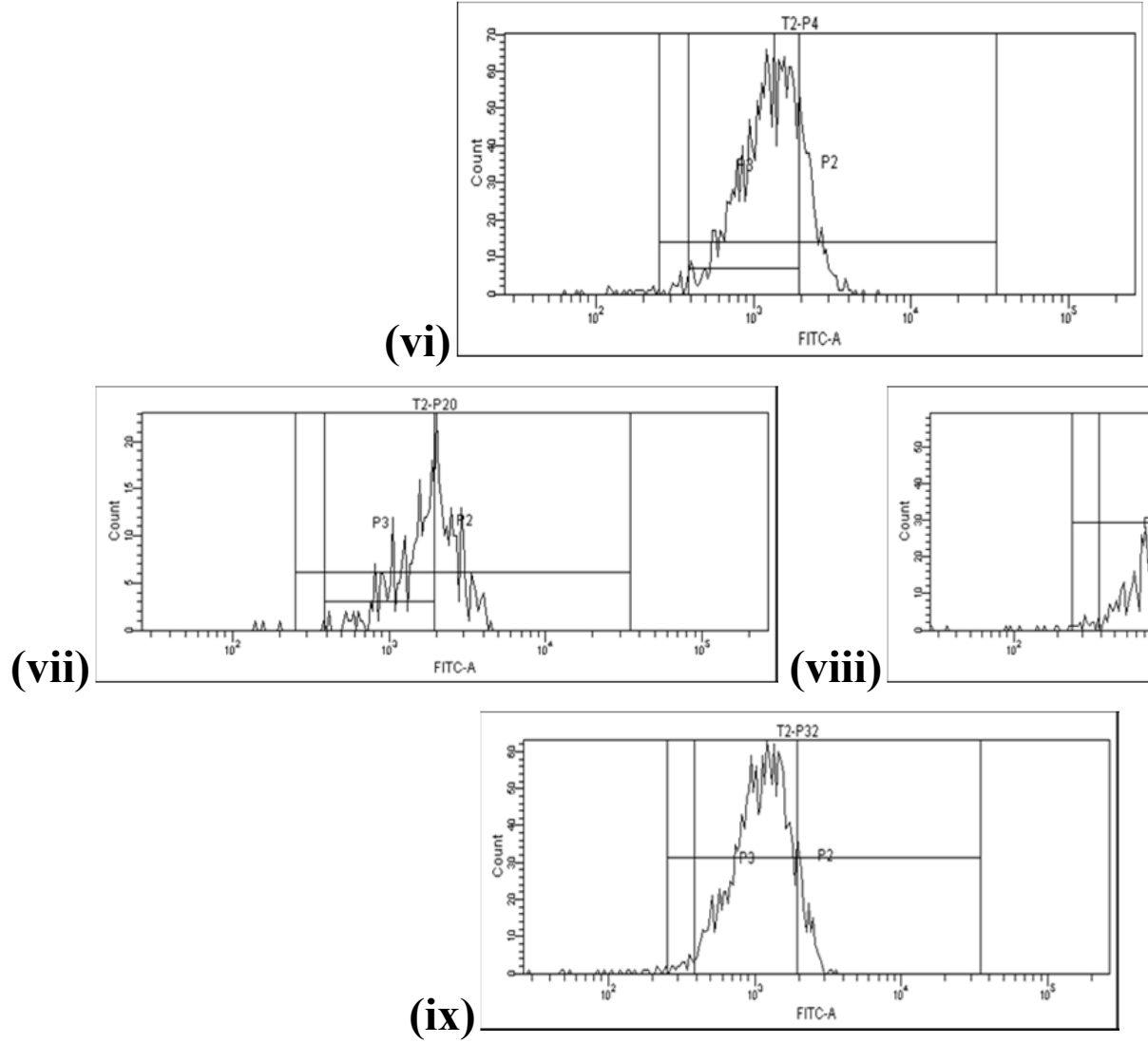
With HSV-1 sequence conservation between $66.7 \%$ and $100 \%$ (6/9 to $9 / 9$ amino acid identity, shown in Table 3) and reports describing T cell responses in HSV-2 seronegative individuals [29], we screened HLA-A*02+ healthy donors and established peptide derived $\mathrm{T}$ cell lines from repetitive peptide pulsing from donor 1185 (Figure 3 ). We were able to identify peptide specific $\mathrm{T}$ cell responses

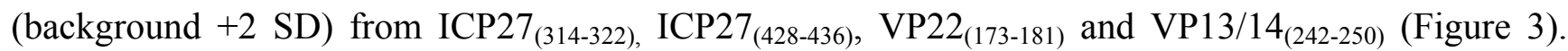
This finding indicates a presence of a small frequency of functionally reactive peptide specific $\mathrm{T}$ cells able to respond to peptide stimulation. Ex vivo screening and phenotyping of T cells derived from both healthy donors and HSV-2 positive patients using peptide-MHC tetrameric complexes may provide additional information on frequency and functionality of HSV-2 specific T cells. Table 3 summarizes the HLA-A2 epitopes identified in this study.

Table 3. Summary of epitopes identified from HSV-2 proteins in a healthy human HLA-A2+ donor (1185) with \% sequence homology to HSV-1. The set threshold for high affinity binding peptides was given an $\mathrm{AI}$ of $\geq 1.5$, and for intermediate affinity peptides was given an AI of 1.25-1.5.

\begin{tabular}{|c|c|c|c|c|}
\hline $\begin{array}{c}\text { HLA-A2 Restricted } \\
\text { Epitope }\end{array}$ & $\begin{array}{c}\text { Peptide } \\
\text { Sequence }\end{array}$ & $\begin{array}{c}\text { \% SEQUENCE } \\
\text { Homology to HSV-1 }\end{array}$ & $\begin{array}{c}\text { Affinity } \\
\text { Index (AI) }\end{array}$ & $\begin{array}{c}\text { Mean SFU/million } \\
\text { PBL }\end{array}$ \\
\hline ICP27(314-322) & TLVAHGPSL & 100 & 1.70 & 377.5 \\
\hline ICP27(428-436) & FVLVILARL & $88.8 \%$ & 1.42 & 107.5 \\
\hline VP22(173-181) & AKKLHFSTA & $88.8 \%$ & 1.28 & 152.5 \\
\hline VP13/14(242-250) & FASPADPKV & $66.7 \%$ & 1.61 & 132.5 \\
\hline
\end{tabular}

${ }^{a}$ Alignments were performed using genebank HSV-1 ICP27 accession AB235845.1, HSV-1 VP22 accession NP_044651, HSV-1 VP13/14 accession NP_044649. HSV-2 alignments were performed with ICP27 accession NP_044525, VP22 accession NP_044519, VP13/14 accession ABS84906; ${ }^{\mathrm{b}}$ Assessed by T2 stabilization. Affinity index $>1.5$ high affinity, 1.25-1.49 was considered as an intermediate affinity peptide.

Figure 3. Generation and expansion of $H S V-2$ peptide specific T cells from an HLA-A*02+ donor (1185): PBL were derived from an HLA-A*02+ donor and stimulated with peptides from ICP27 (314-322), ICP27 $_{(428-436),}$ VP22 $2_{(146-154),}$ VP22 $2_{(173-181)}$ and VP13/14(242-150). After 4 stimulations cells were assessed for peptide specific responses by an overnight IFN- $\gamma$ ELISpot assay. This figure represents the original count data from the ELISpot plate with standard deviations (SD).

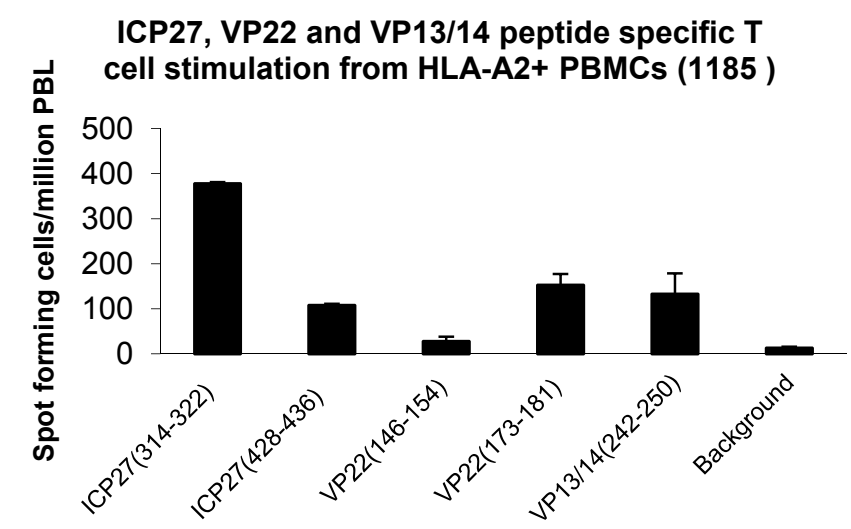


During the course of the present study, two papers were published that described peptide selection, pre-clinical efficacy [32] and Phase I clinical trial [33] data for a polyvalent anti-HSV-2 vaccine consisting of 32 peptides from HSV-2 proteins. These studies included a single 35 amino acid peptide from ICP27 (amino acids 410-444), but did not include any peptides from VP22 or VP13/14. The aim of those studies was to generate both CD4+ and CD8+ cellular immunity. We have described a peptide from the same region of ICP27 (amino acids 428-436) with an intermediate affinity for HLA-A2 that induced reactive CD8+ T cells in natural infection (Table 3 ) and also described a further peptide from ICP27 (314-322) that had a higher affinity for HLA-A2 (Figure 2A), and a stronger response in our donor (Table 3). It is not apparent from the published preclinical study what impact the ICP27 peptide had in the vaccine, nor is it possible to say whether the alternative peptide we identified would improve efficacy. However, it is important for future vaccine design to be able to identify the best candidate peptides for driving strong immune responses that can provide clinical efficacy.

\subsection{HSV-2 DNA Vaccines Delivered by PMED Generate High Frequencies of CD8+ Peptide Specific T Cells}

Full length DNA vaccines encoding codon optimized ICP27, VP22 and VP13/14 sequences were constructed for vaccine delivery using the PMED device. DNA vaccine delivery using the PMED gene gun has demonstrated success in the clinic and provides a safe and alternative approach to needle based intramuscular delivery requiring milligrams of DNA [34-36]. Gold particles containing $2 \mu \mathrm{g}$ of DNA were given as a single actuation to the shaved abdomen of BALB/c mice without adjuvant. Mice were then given a second booster vaccine 29 days after the primary immunization. Spleens were removed on day 40 to assess $\mathrm{T}$ cell responses using IFN- $\gamma$ ELISpot and mobilization of CD107a after peptide stimulation (Figure $4 \mathrm{~A}-\mathrm{G}$ and Table 2). Table 2 shows the peptide specific IFN-Y ELISpot responses after DNA vaccination to each HSV-2 protein. Strong ICP27 specific responses were observed to the previously unidentified ICP2 $7_{(500-508)}$ epitope $(247 \mathrm{SFC} /$ million PBL), with the strongest response restricted to the ICP27 $7_{(318-326)}$ epitope (304 SFC/million PBL). Interestingly no other $\mathrm{T}$ cell responses were seen to epitopes that elicited ICP27 specific T cells after HSV-2 infection. This finding suggests that vaccine driven responses to ICP27 generated $\mathrm{T}$ cells to immunodominant sequences. CD107a mobilization shows broad degranulation of ICP27 peptide specific CD8+ T cells with frequencies in excess of background levels (Figure 4B, E and F). Interestingly, IFN-Y positive responses were only seen for the VP22 (200-208) epitope after VP22 DNA immunization. In contrast, $3.6 \%$ and $1.7 \%$ (including irrelevant peptide background subtraction) of total CD8+ $\mathrm{T}$ cells degranulated after VP22 $2_{(46-54)}$ and VP22 $2_{(200-208)}$ after peptide stimulation respectively (Figure $4 \mathrm{~B}$ and C). Collectively, this data illustrates potential immunodominance and broad functionality of cytokine secreting CD8 $+\mathrm{T}$ cells raised after DNA immunization. Similarly like ICP27, strong IFN-Y T cell responses were observed to the VP22 epitopes, VP22(46-54), VP22(171-179) and VP22(200-208) after infection with HSV-2. CD8+ T cells degranulating in response to VP13/14 ${ }_{(244-252)}$ and VP13/14(592-600) peptide stimulation after VP13/14 DNA immunization were present at a modest frequency of $1.3 \%$ of total CD8+ T cells. 
Figure 4. Mobilization of CD107a on peptide specific CD8+ T cells after DNA vaccine administration encoding the HSV-2 ICP27, VP22 and VP13/14 antigens. (A) BALB/c mice $(n=6)$ were immunized using the DNA prime-boost regimen using particle mediated epidermal delivery with full length monovalent vaccines (ICP27, VP22 and VP13/14). On day 40 splenocytes were harvested, pooled in their respective groups and pulsed with peptide for 4 hours in the presence of anti-CD107a-FITC antibody. (B) FACS plots are shown as CD107a+/CD8 + T cells as a percentage of total CD8 + T cells for VP22, VP13/14 and ICP27 peptide specific response. Irrelevant peptide control and ConA CD107a+/CD8+ responses are shown as negative and positive controls for CD107a degranulation. (C, D, E, F) Percentage of CD107a+/CD8+ T cell responses shown with irrelevant peptide responses subtracted from the total CD107a+/CD8 + T cell percentages for each of the HSV-2 DNA immunization group. (E) Graph showing CD107a+/CD8+ $\mathrm{T}$ cell responses in mice immunized with a mock antigen and pulsed with ICP27, VP22 and VP13/14 peptides.

(G) Graph showing CD107a+, CD8+ T cell degranulation after ConA stimulation.

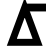

Day 0

(DNA

Prime with PMED device)

(A)

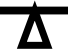

Day 29

(DNA

Boost)
Day 40

(Splenectomy for

Immunomonitoring)

CD107
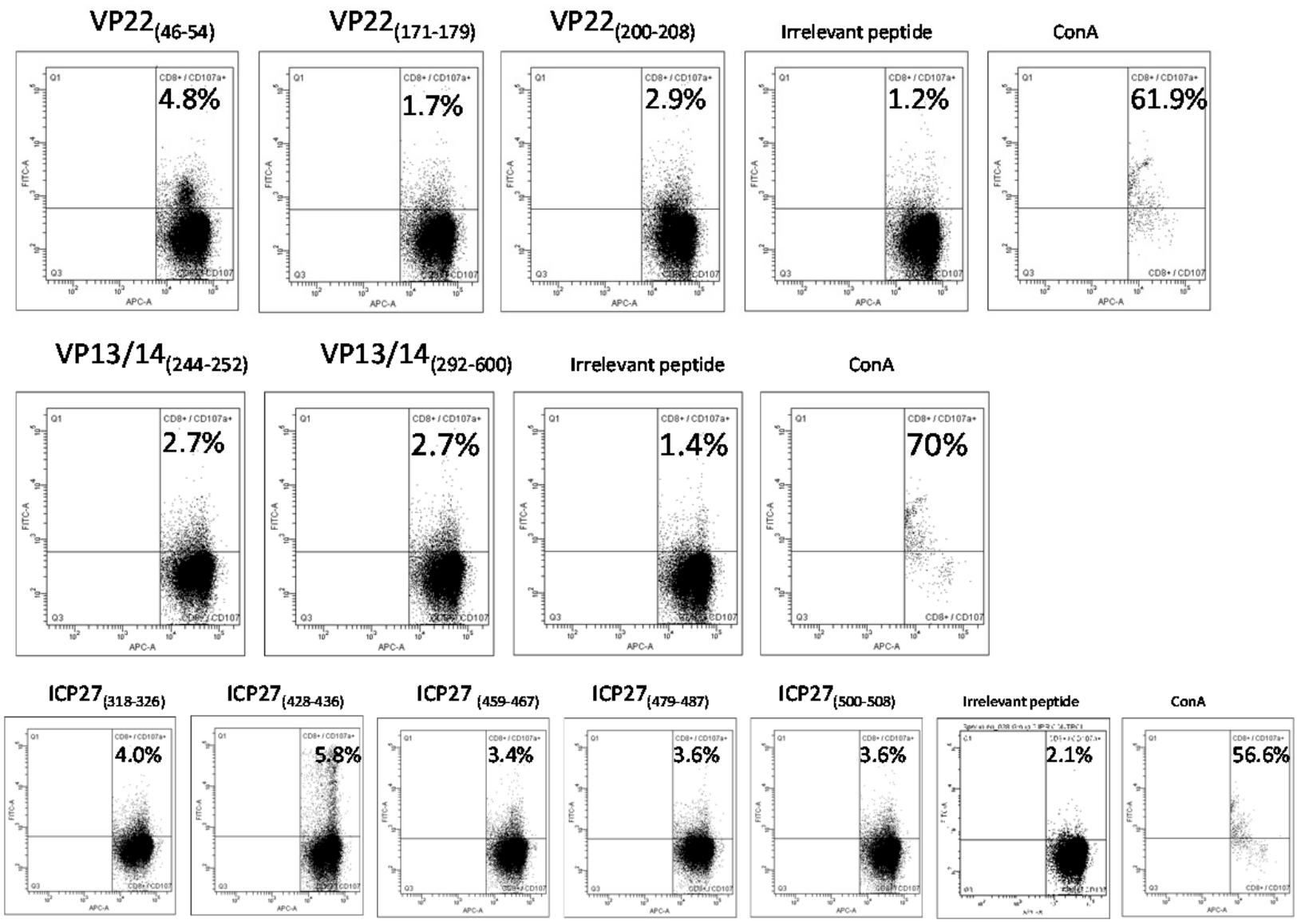

(B) 
Figure 4. Cont.

Epitope specific CD8+ T cell responses after homologous VP13/14 DNA prime boost using gold particle mediated epidermal delivery

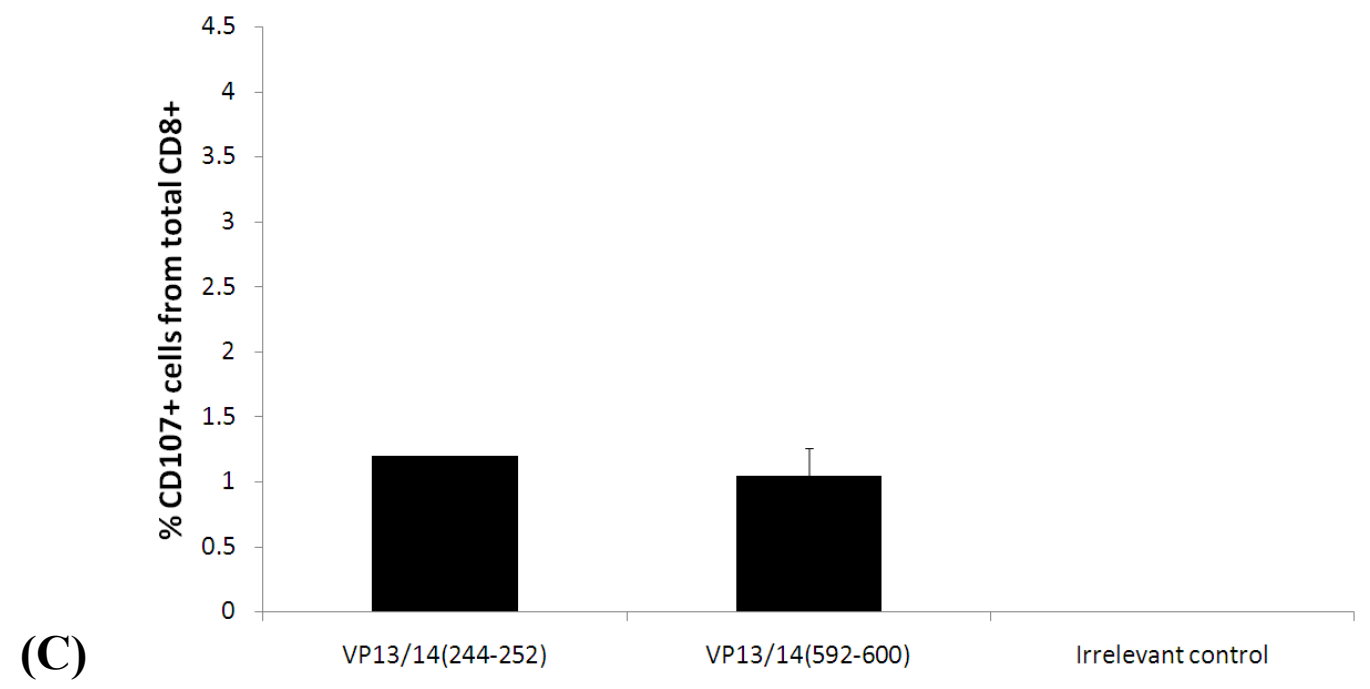

Epitope specific $\mathrm{CD} 8+\mathrm{T}$ cell responses after mock antigen DNA prime boost using gold particle mediated epidermal delivery

(D)
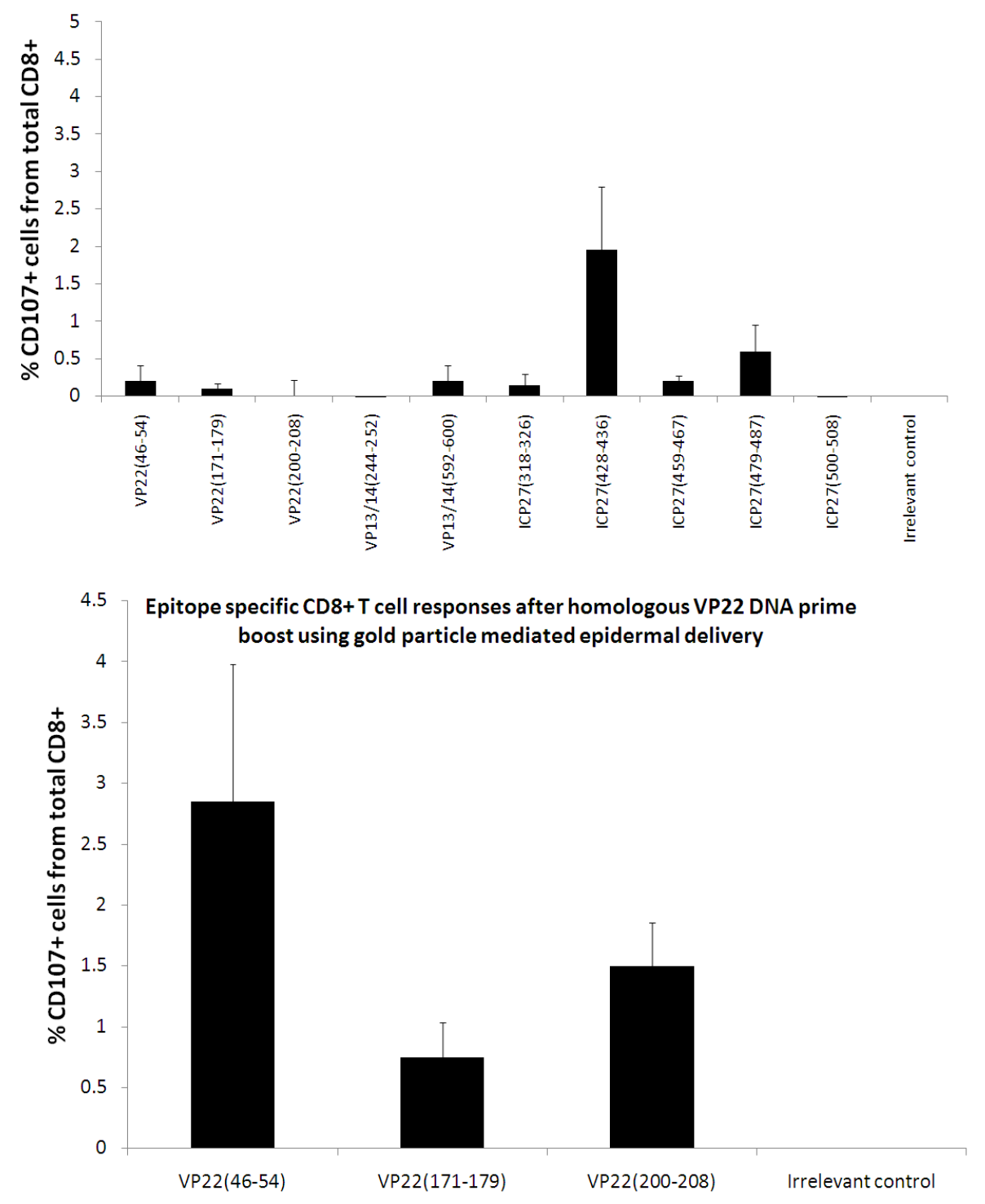

(E) 
Figure 4. Cont.

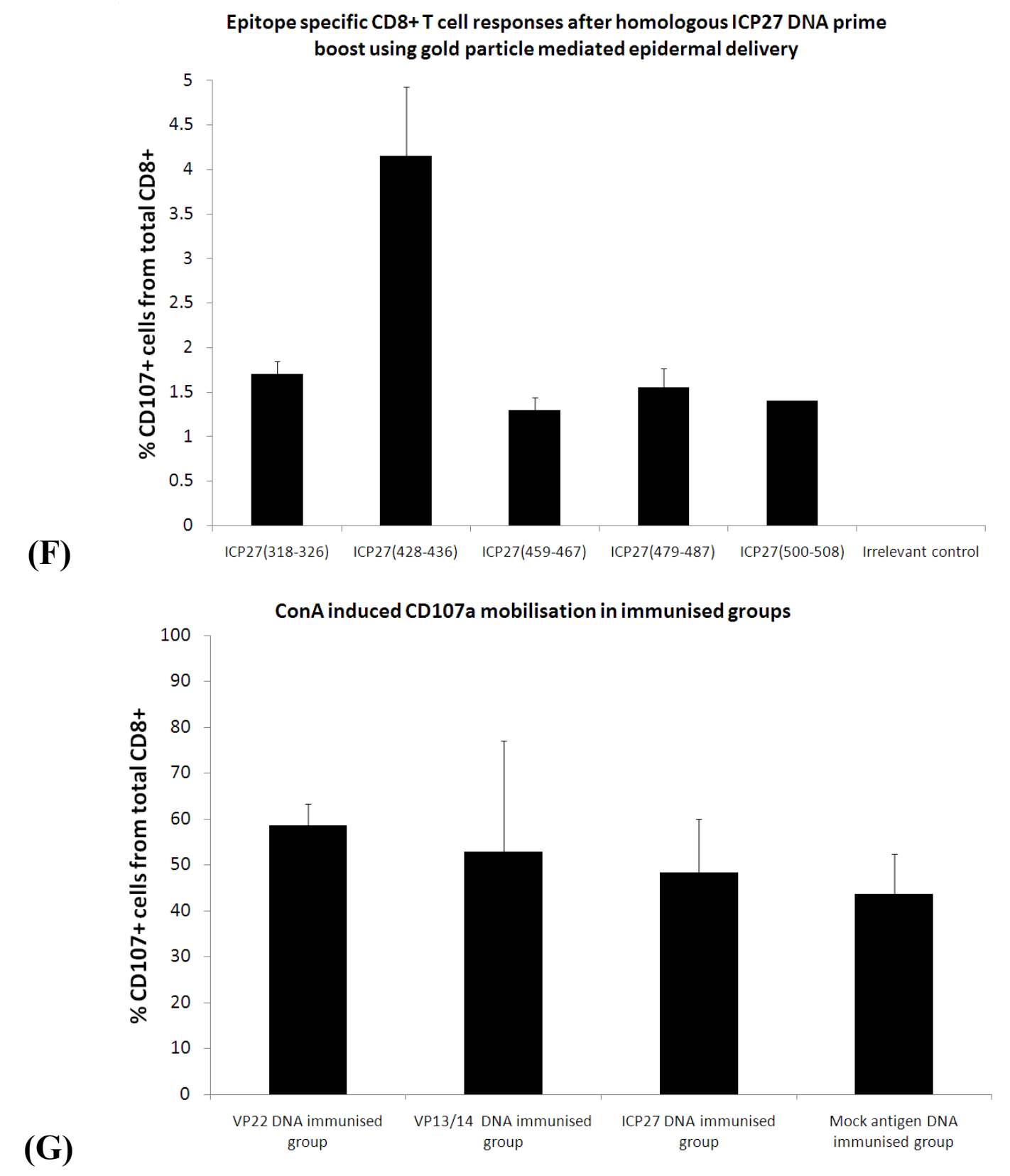

\subsection{Potential Role of ICP27 in Protection Against HSV Challenge Following Immunization}

Specific cellular responses to ICP27 were generated both by infection and by DNA vaccination. Vaccinated mice were challenged with HSV-2 to investigate the potential of these responses to protect against infection in both intravaginal and intranasal challenge models. Vaccination of mice with ICP27 provided protection against viral shedding in the intravaginal model, with five out of eight animals shedding no virus at either one or four days post infection compared with three out of eight controls (Figure 5A). Mean viral titers were 225 and 8590 for vaccinated and unvaccinated groups at day four post-infection, respectively. Vaccinated mice demonstrated a trend towards lower clinical scores than unvaccinated counterparts, although this was not demonstrably significant (Figure 5B). Vaccination with ICP27 was more protective in the intranasal challenge model, with vaccinated mice showing reduced clinical scores and a delayed onset of more significant disease (Figure 5C). 
Figure 5. A role for ICP27 in protection against HSV challenge following immunization. A DNA vaccine against ICP27 was used to immunize mice prior to challenge with HSV-2 in intravaginal (A, B) and intranasal (C) models of infection. A) Virus shedding was detected by viral plaque assays at days 1 (closed circles) and 4 (closed squares) post infection. B) Mean clinical score for ICP27 vaccinated (open squares) and naive (crosses) groups at each day for fourteen days post-infection. C) Mean clinical scores for ICP27 vaccinated (closed triangle), mock vaccinated (open rhombus) and naive (closed squares) groups at each day for fourteen days post-infection.
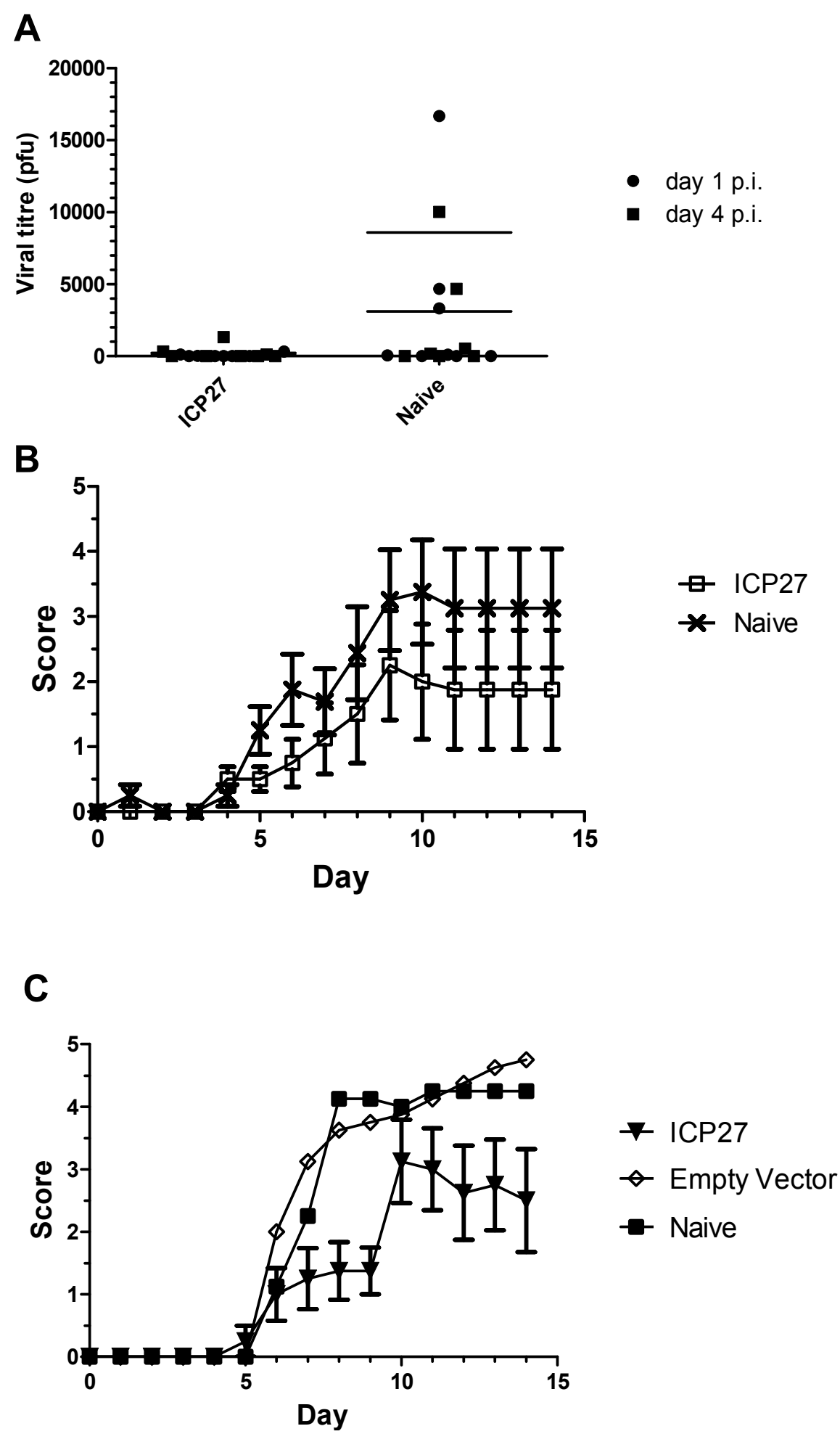
T cell control in establishing latency in HSV-2 infection is not fully understood. Additional work using T cell lines and clones sorted from HSV-2 patients in transwell and migration experiments may allow better understanding of therapeutic approaches to control or eliminate HSV-2 from infected cells. CD8+ T cell recruitment to sites of infection has recently been shown to depend heavily upon CXCR3+ CD4+ T cell induced mobilization through the CXCL9 and CXCL10 gradient [37]. This important finding suggests that vaccines should be designed to induce both CD8+ T cells with CD4+ T cell help. Live imaging techniques using antigen specific $\mathrm{T}$ cell adoptive transfer experiments in RAG knockout mice would provide valuable data on localization of T cells and subsequent mode of action.

It has been shown for vaccinia virus that the route of infection may skew peptide specific responses to certain epitopes or enhance and diminish dominant CD8+ T cell responses [38-40]. In this study, we have not assessed intra-ocular or other routes of infection. Furthermore, rational single amino acid modifications to peptides known to elicit a stimulatory response may enhance immunogenicity and therefore result in a more favorable outcome in an epitope based vaccine and disease challenge setting [41]. ICP27, VP22 and VP13/14 DNA vaccines delivered using the PMED ND10 device elicited strong CD107a+/CD8 $+\mathrm{T}$ cells after peptide stimulation. It is interesting to note that the peptide specific $\mathrm{T}$ cell frequencies could not be compared between $\mathrm{T}$ cells positive for CD107a expression and IFN-Y ELISpot after peptide stimulation. Furthermore, BALB/c mice infected with HSV-2 showed a greater frequency of T cells specific for ICP27 and VP22 epitopes than mice immunized with DNA vaccines (Table 2). It is important to note that mice infected with HSV-2 also displayed a greater coverage of epitope specific responses than with DNA vaccination which skewed ICP27 and VP22 specific responses to ICP27 $7_{(318-326),}$ ICP27 $7_{(500-508)}$ and VP22 $2_{(200-208)}$ epitopes. Due to the polyfunctional nature of $\mathrm{T}$ cells generated through vaccination, further work is required to dissect the proportion of HSV-2 pentamer/tetramer specific CD8+/CD107a+ cells capable of mounting IFN$\mathrm{Y}^{+}$, IL-2+ and TNF- $\alpha+$ responses. Further translational experiments using HLA-A*02 restricted epitopes described in this study on HLA-A*02+ infected transgenic mice or HSV-2 seropositive donors may provide a clearer understanding of the frequency and functionality from ICP27, VP22 and VP13/14 restricted T cells ex vivo. Additionally for vaccine development, translational experiments using in vitro DC:T cell co-culture experiments would provide a clearer understanding of the immunogenicity and functionality of HLA restricted HSV-2 epitopes.

\section{Experimental Section}

\subsection{Peptide Selection for HSV-2 ICP27, VP22 and VP13/13 Epitopes}

An initial screening of responses to peptides was performed with 15 mer peptides overlapping by 10 amino acids derived from ICP27 (Accession number, NP_044525, version GI: 9629325), VP22 (NP_044519, GI: 9629319) and VP13/14 (ABS84906, GI: 154744659) (Data not shown). Peptides were synthesized by Sigma-Aldrich Corp, St. Louis, MO. Sequences that were found to give positive responses were then selected for subsequent fine mapping and characterization. Peptide selection was restricted to peptides spanning 9 amino acids and was performed on mouse MHC class I molecules for H2-Dd, H2-Kd, H2-Ld and human HLA-A*0201 using the Immune Epitope Database (IEDB) [24]. In total, 44 peptides were selected with theoretical IC50 values ranging from 21.5 to $45487.2 \mathrm{nM}$ 
spanning selected regions of ICP27, VP22 and VP13/14 proteins, as shown in Table 1. Overlapping amino acid sequences of differing IC50 values spanning 15-mer sequences were included to assess the impact of residue modifications on the extent of immunogenicity.

\subsection{Peptide Synthesis}

Peptides of 9 amino acids in length were synthesized at $>85 \%$ purity for epitope mapping (Sigma-Aldrich). In total 44 peptides were obtained and dissolved in 100\% DMSO (Sigma) at a stock concentration of $10 \mathrm{mg} / \mathrm{mL}$. Peptides were used at a final concentration of $50 \mu \mathrm{g} / \mathrm{mL}$ unless otherwise stated. For peptide stabilization studies the well defined HLA-A*0201 sequence from Influenza Matrix Protein M1 GILGFVFTL $(58$ - 66) was used as a positive control (Anaspec, CA, US) [42].

\subsection{Animals}

Six to eight week old female BALB/c mice (Charles River, UK) were used in the studies. All experiments were carried out in compliance with the UK legislation and subject to local ethical review. Humane endpoints were strictly adhered to.

\subsection{Intravaginal HSV-2 Challenge Model}

Six days prior to infection, mice were given $20 \mu \mathrm{g}$ of Depo Provera (Medroxyprogesterone) (Pfizer, Ltd) subcutaneously to ensure mice enter diestrus when infected. On day 0 , mice $(n=10)$ were infected with $1 \times 10^{3}$ pfu of HSV-2 strain 333 in a total volume of $20 \mu \mathrm{L}$ PBS by intravaginal administration. The control group $(n=2)$ were given PBS by the intravaginal route. On days 1 and 4 post-infection, vaginal lavage was collected by pipeting $50 \mu \mathrm{L}$ of phosphate buffered saline in and out of the vagina several times, transferred to vials and stored at $-80{ }^{\circ} \mathrm{C}$ until assayed for viral load using plaque assay. Mice were monitored for 14 days and their health was checked daily using a clinical score system and by recording body weight. Pathology was assessed using a 5-point score as follows: Healthy - no apparent infection $=0$, Slight redness $=1$, Redness and swelling $=2$, Severe redness of surrounding area $=3$, Ulceration and/or hair-loss $=4$, score of 4 in addition to 2 additional clinical signs $=5$. All procedures were carried out under the authority of a UK home office project license and in accordance with UK governmental regulations (Animal Scientific Procedures Act 1986).

\subsection{Intranasal HSV-2 Challenge Model}

Groups of eight to ten mice were lightly anesthetized under general anesthesia Isoflurane and $50 \mu 1$ of $10^{5}$ or $10^{6}$ pfu HSV-2 strain 333 was slowly pipeted onto the tip of the nose. The mice were kept on their backs until complete recovery from anesthesia. Following infection mice were weighed and scored daily (by operators who were blinded as to the identity of the treatment groups) using the following clinical scores: $0=$ no apparent infection, $1=$ piloerection and/or breathing difficulties, $2=$ reduced movement/dull squinting eyes, $3=$ sores on eyes, ocular discharge and/or hunched, $4=$ symptoms above $3,5=$ severe respiration difficulties, $6=$ paralysis. Any mouse approaching a score of 5 was sacrificed. 


\subsection{Viral Plaque Assays}

Vero cells were grown to confluence in 12 well plates. Samples were diluted in EMEM medium and added to the confluent monolayers followed by a one hour incubation period at $37{ }^{\circ} \mathrm{C}$. The inoculum was then removed and $1 \mathrm{ml}$ of overlay (4\% Carboxymethyl cellulose) solution was added and incubated for another 2 to 3 days at $37{ }^{\circ} \mathrm{C}$. One hour prior to reading the plates, $1 \mathrm{~mL}$ of $2 \%$ neutral red solution was added to enhance the visibility of the plaques.

\subsection{ELISpot}

Splenocytes from infected mice were harvested by mechanical disruption and washed twice in serum free cell culture media. The splenocytes were then resuspended in R10 and plated out on IFN- $\Upsilon$ (7.5 $\mu \mathrm{g} / \mathrm{mL}$, AN18 or 1-DK1 diluted in PBS with $0.5 \%$ FCS), (Mabtech, Sweden), coated PVDF (polyvinylidene difluoride)-backed microplate (Millipore), at a concentration of $5 \times 10^{5}$ cells/well. Prior to the addition of the splenocytes, the PVDF plates were washed and blocked with $10 \%$ FCS (Sigma) for $4 \mathrm{~h}$ at $37{ }^{\circ} \mathrm{C}$. Individual HSV-2 9mer peptides at a final concentration of $20 \mu \mathrm{g} / \mathrm{mL}$ were then added to the wells and cultured for $18 \mathrm{hr}$ at $37{ }^{\circ} \mathrm{C}$, in a humid $5 \% \mathrm{CO}_{2}$ incubator. The next day the plate was developed using the manufacturer's instructions (Mabtech, Sweden). Spots were read and counted on an automated ELISpot counter (AID Diagnostika GmbH). Results are expressed in Spot Forming Cells (SFC) per $5 \times 10^{5}$ cells with standard error means (SEM). Responses equal to or greater than 90 SFC per million splenocytes were considered positive responses.

\subsection{Cell Lines}

T2 $(174 \times$ CEM.T2) mutant hybrid cell line derived from the T-lymphoblast cell line CEM was obtained from the ATCC. T2 cells lack the functional transporter associated with antigen processing (TAP) heterodimer and fail to express normal amounts of HLA-A*0201 on the cell surface. HLA-A*0201 surface expression can be stabilized with exogenous loading of peptide able to bind to the MHC class I molecule. The T2 cell line was maintained in RPMI 1640 (Sigma-Aldrich) supplemented with $10 \%$ heat-inactivated fetal calf serum (FCS) and $100 \mathrm{U}$ of penicillin/mL, $100 \mathrm{U}$ of streptomycin/ml (collectively called R10) (Sigma-Aldrich).

\subsection{Detection of CD107a Mobilization in T cells}

CD8 $+\mathrm{T}$ cell degranulation has been shown to be a prerequisite for perforin and granzyme mediated cell lysis [43]. Degranulation can be measured by the mobilization of CD107a/LAMP-1 from the lysosomal membrane compartment to the cell surface which results in the increase of CD107a cell surface expression [44]. Briefly, $2 \times 10^{6}$ of mixed splenocytes were transferred into 96-well V bottom FACS plates (BD) in R10 media medium and stimulated with peptide $(2 \mu \mathrm{g} / \mathrm{mL})$ in the presence of anti-CD107a-FITC (BD Pharmingen) (1 $\mu \mathrm{g} /$ well) for 4 hours. ConA $(10 \mu \mathrm{g} / \mathrm{mL})$ (Sigma) and irrelevant peptide were used as positive and negative controls, respectively. Cells were then washed and stained with anti-CD8-APC and anti-CD4-PE antibodies (BD Pharmingen). The cells were washed and fixed using cytofix solution (BD Biosciences) according to manufacturer's instructions. A minimum of $1 \times 10^{6}$ cells were acquired on an FACS canto II using a 96well HTS module (BD Biosciences). 
Analysis was performed using FACS Diva. Frequencies are presented as a percentage of CD107a positive cells from total CD8+ cells with the irrelevant control frequencies subtracted.

\subsection{Peptide-induced T2 stabilization assay}

$\mathrm{T} 2$ cells were cultured in R10 media in $5 \% \mathrm{CO}_{2}$ at $37^{\circ} \mathrm{C}$. Peptides from ICP27, VP22 and VP13/13 were tested for their ability to bind to and stabilize HLA-A*02 molecules on the surface of T2 cells. T2 cells $\left(2 \times 10^{5}\right)$ were suspended in R10 media and distributed into 96-well plates (BD). The cells were incubated with the peptides at $50 \mu \mathrm{g} / \mathrm{mL}$ final concentration. The media was also supplemented with $\beta_{2}$-microglobulin (Sigma) at $2.5 \mu \mathrm{g} / \mathrm{mL}$ for $18 \mathrm{~h}$ at $37{ }^{\circ} \mathrm{C}$. The $\mathrm{T} 2$ cells were then stained with anti-HLA-A*02-FITC BB7.2 monoclonal antibody (BD Pharmingen) and analyzed after 20 minutes on ice. The number of stabilized HLA-A*02 molecules on the surface of T2 cells was determined by fluorescent intensity. The ability of the peptide to combine with the HLA-A*02 was calculated as follows: $\mathrm{AI}=\left(\mathrm{MFI}_{1}-\mathrm{MFI}_{0}\right) /\left(\mathrm{MFI}_{2}-\mathrm{MFI}_{0}\right)$, where $\mathrm{AI}$ is the affinity index for HLA-A*02, $\mathrm{MFI}_{1}$ is the mean fluorescence index (MFI) of staining T2 cells treated with the peptide, $\mathrm{MFI}_{2}$ is the MFI of staining T2 cells without peptide treatment, and $\mathrm{MFI}_{0}$ is the MFI of $\mathrm{T} 2$ cell staining with an isotype control antibody. AI peptide scores equal to or greater than 1.5 displayed high affinity, 1.25-1.49 intermediate affinity and 1.1-1.25 were regarded as low affinity peptide as previously described [27]. Peptide specific $\mathrm{T}$ cells were generated from healthy donors using peptides that displayed intermediate and high affinity binding to T2 cells.

\subsection{In vitro Peptide Specific T Cell Proliferation}

To obtain peptide specific $\mathrm{T}$ cells, PBL were taken from healthy donors who were HLA-A*02 positive and processed as described previously [45]. PBL donor lymphocytes (1185) were pulsed every 10 days with $25 \mu \mathrm{g} / \mathrm{mL}$ of selected peptides in the presence of IMDM, 5\% human serum (Sigma) and 200 units/mL IL-2 (R\&D systems). Cells that responded to HSV-2 peptide were later maintained in $25 \mathrm{ng} / \mathrm{ml}$ IL-15 (R\&D Systems, Minneapolis, MN) to allow low level proliferation and survival.

\subsection{Generation and Expansion of HSV-2 Peptide Specific T Cells from a Healthy HLA-A*02+donor.}

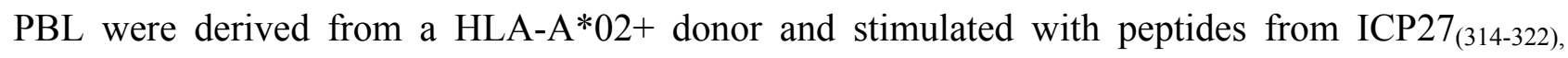
$\mathrm{ICP}_{\text {24 }}(428-436), \mathrm{VP}_{(146-154)}, \mathrm{VP} 22_{(173-181)}$ and VP13/14(242-150). Stimulations were performed with a one hour pulse of $20 \mu \mathrm{g} / \mathrm{mL}$ peptide and $25 \mathrm{ng}$ IL-15 prior to growth for seven days. ELISpots were performed after each stimulation to monitor progress. After 4 stimulations cells were assessed for peptide specific responses by an overnight IFN- $\gamma$ ELISpot assay. ELISpots were performed as described above, using Mabtech human IFN- $\gamma$ ELISpot kit (Mabtech, Sweden).

\subsection{DNA Vaccine Construction and Immunization}

DNA vaccines were constructed and formulated onto gold particles for PMED delivery using methods previously described [46]. Briefly, codon optimized cDNA sequences of ICP27, VP22 and VP13/14 were synthesized (GeneArt AG, Regensburg, Germany) and subcloned into pPML7857, pPML7858 and pPML7871 plasmids respectively. Recombinant mRNA expression was confirmed for 
all vectors by RT-PCR following transfection of $\mathrm{CHO}$ cells. Monovalent DNA vaccines for each plasmid were precipitated onto gold beads ranging from 1-3 $\mu \mathrm{m}$ in diameter and filled into cassettes for helium accelerated DNA-gold particle delivery by the single use ND10 device [46]. Each actuation of the ND10 device was formulated to deliver $2 \mu \mathrm{g}$ of DNA on $1 \mathrm{mg}$ of gold. BALB/c mice $(\mathrm{n}=6)$ (6-8 weeks old) were intradermally immunized with a single actuation from the ND10 device encoding the DNA constructs on gold [23]. All immunization procedures were carried out under the authority of a UK home office project license.

\section{Conclusions}

We have used linear based epitope detection methods to characterize several potential CD8+ T cell epitopes from HSV-2 proteins ICP27, VP22 and VP13/14 in an HSV-2 infection model in BALB/c mice. Experimental validation was performed using the HSV-2 infected mouse model and the results compared with responses elicited by DNA encoded vaccines. Responses were shown by ELISpot generally to be of a higher magnitude in the infection model than in vaccinated animals. These epitopes could be used to monitor peptide specific $\mathrm{T}$ cell responses after DNA vaccine delivery with the HSV-2 antigens ICP27, VP22 and VP13/14. It is possible that an optimized vaccination strategy may generate a sufficiently strong and broad response to mimic the responses seen in the infected animals.

\section{Acknowledgments}

The authors would like to thank Claire Lees and Phil White for construction and formulation of DNA for PMED vaccine delivery. The authors also wish to thank Jim Eyles for carrying out the DNA immunizations and maintaining animal care.

\section{Conflict of Interest}

P.C., R.W., B.C. and T.P.H are employees and shareholders of Pfizer Inc.

\section{References and Notes}

1. Looker, K.J.; Garnett, G.P.; Schmid, G.P. An estimate of the global prevalence and incidence of herpes simplex virus type 2 infection. Bull. World Health Organ. 2008, 86, 805-812.

2. Senior, K. Herpes simplex type 2 infects one in ten globally. Lancet Infectious Dis. 2009, 9, 15-15.

3. Corey, L.; Langenberg, A.G.M.; Ashley, R.; Sekulovich, R.E.; Izu, A.E.; Douglas, J.M., Jr.; Handsfield, H.H.; Warren, T.; Marr, L.; Tyring, S.; DiCarlo, R.; Adimora, A.A.; Leone, P.; Dekker, C.L.; Burke, R.L.; Leong, W.P.; Straus, S.E. Recombinant Glycoprotein Vaccine for the Prevention of Genital HSV-2 Infection: Two Randomized Controlled Trials. JAMA 1999, 282, 331-340.

4. Langenberg, A.G.; Burke, R.L.; Adair, S.F.; Sekulovich, R.; Tigges, M.; Dekker, C.L.; Corey, L. A recombinant glycoprotein vaccine for herpes simplex virus type 2: Safety and immunogenicity [corrected]. Ann. Intern. Med. 1995, 122, 889-898. 
5. Bernstein, D.I.; Aoki, F.Y.; Tyring, S.K.; Stanberry, L.R.; St-Pierre, C.; Shafran, S.D.; Leroux-Roels, G.; Van Herck, K.; Bollaerts, A.; Dubin, G. Safety and immunogenicity of glycoprotein D-adjuvant genital herpes vaccine. Clin Infect. Dis 2005, 40, 1271-1281.

6. Stanberry, L.R.; Spruance, S.L.; Cunningham, A.L.; Bernstein, D.I.; Mindel, A.; Sacks, S.; Tyring, S.; Aoki, F.Y.; Slaoui, M.; Denis, M.; Vandepapeliere, P.; Dubin, G.; The GlaxoSmithKline Herpes Vaccine Efficacy Study Group. Glycoprotein-D-Adjuvant Vaccine to Prevent Genital Herpes. N. Engl. J. Med. 2002, 347, 1652-1661.

7. Hoshino, Y.; Pesnicak, L.; Dowdell, K.C.; Lacayo, J.; Dudek, T.; Knipe, D.M.; Straus, S.E.; Cohen, J.I. Comparison of immunogenicity and protective efficacy of genital herpes vaccine candidates herpes simplex virus $2 \mathrm{d15}-29$ and d15-29-41L in mice and guinea pigs. Vaccine 2008, 26, 4034-4040.

8. Muller, W.J.; Dong, L.; Vilalta, A.; Byrd, B.; Wilhelm, K.M.; McClurkan, C.L.; Margalith, M.; Liu, C.; Kaslow, D.; Sidney, J.; Sette, A.; Koelle, D.M. Herpes simplex virus type 2 tegument proteins contain subdominant $\mathrm{T}$-cell epitopes detectable in BALB/c mice after DNA immunization and infection. J. Gen. Virol. 2009, 90, 1153-1163.

9. Zhang, X.; Chentoufi, A.A.; Dasgupta, G.; Nesburn, A.B.; Wu, M.; Zhu, X.; Carpenter, D.; Wechsler, S.L.; You, S.; BenMohamed, L. A genital tract peptide epitope vaccine targeting TLR2 efficiently induces local and systemic CD8+ T cells and protects against herpes simplex virus type 2 challenge. Mucosal. Immunol. 2009, 2, 129-143.

10. Wakim, L.M.; Jones, C.M.; Gebhardt, T.; Preston, C.M.; Carbone, F.R. CD8+ T-cell attenuation of cutaneous herpes simplex virus infection reduces the average viral copy number of the ensuing latent infection. Immunol. Cell. Biol. 2008, 86, 666-675.

11. Khanna, K.M.; Bonneau, R.H.; Kinchington, P.R.; Hendricks, R.L. Herpes simplex virus-specific memory CD8+ T cells are selectively activated and retained in latently infected sensory ganglia. Immunity 2003, 18, 593-603.

12. Zhu, J.; Koelle, D.M.; Cao, J.; Vazquez, J.; Huang, M.L.; Hladik, F.; Wald, A.; Corey, L. Virusspecific CD8+ T cells accumulate near sensory nerve endings in genital skin during subclinical HSV-2 reactivation. J. Exp. Med. 2007, 204, 595-603.

13. Dobbs, M.E.; Strasser, J.E.; Chu, C.F.; Chalk, C.; Milligan, G.N. Clearance of herpes simplex virus type 2 by $\mathrm{CD} 8+\mathrm{T}$ cells requires gamma interferon and either perforin- or Fas-mediated cytolytic mechanisms. J. Virol. 2005, 79, 14546-14554.

14. Knickelbein, J.E.; Khanna, K.M.; Yee, M.B.; Baty, C.J.; Kinchington, P.R.; Hendricks, R.L. Noncytotoxic lytic granule-mediated CD8 + T cell inhibition of HSV-1 reactivation from neuronal latency. Science 2008, 322, 268-271.

15. Hoshino, Y.; Pesnicak, L.; Cohen, J.I.; Straus, S.E. Rates of reactivation of latent herpes simplex virus from mouse trigeminal ganglia ex vivo correlate directly with viral load and inversely with number of infiltrating CD8+ T cells. J. Virol. 2007, 81, 8157-8164.

16. Hosken, N.; McGowan, P.; Meier, A.; Koelle, D.M.; Sleath, P.; Wagener, F.; Elliott, M.; Grabstein, K.; Posavad, C.; Corey, L. Diversity of the CD8+ T-Cell Response to Herpes Simplex Virus Type 2 Proteins among Persons with Genital Herpes. J. Virol. 2006, 80, 5509-5515.

17. Braun, R.; Payne, L.; Dong, L. Characterization of the IFN-gamma T-cell responses to immediate early antigens in humans with genital herpes. Virol. J. 2006, 3, 54. 
18. Haynes, J.R.; Arrington, J.; Dong, L.; Braun, R.P.; Payne, L.G. Potent protective cellular immune responses generated by a DNA vaccine encoding HSV-2 ICP27 and the E. coli heat labile enterotoxin. Vaccine 2006, 24, 5016-5026.

19. Kim, T.W.; Hung, C.F.; Kim, J.W.; Juang, J.; Chen, P.J.; He, L.; Boyd, D.A.; Wu, T.C. Vaccination with a DNA vaccine encoding herpes simplex virus type 1 VP22 linked to antigen generates long-term antigen-specific CD8-positive memory $\mathrm{T}$ cells and protective immunity. Hum. Gene Ther. 2004, 15, 167-177.

20. Koelle, D.M.; Chen, H.B.; McClurkan, C.M.; Petersdorf, E.W. Herpes simplex virus type 2-specific CD8 cytotoxic T lymphocyte cross-reactivity against prevalent HLA class I alleles. Blood 2002, 99, 3844-3847.

21. Koelle, D.M.; Liu, Z.; McClurkan, C.L.; Cevallos, R.C.; Vieira, J.; Hosken, N.A.; Meseda, C.A.; Snow, D.C.; Wald, A.; Corey, L. Immunodominance among herpes simplex virus-specific CD8 T cells expressing a tissue-specific homing receptor. Proc. Natl. Acad. Sci. USA 2003, 100, 12899-12904.

22. Koelle, D.M.; Chen, H.B.; Gavin, M.A.; Wald, A.; Kwok, W.W.; Corey, L. CD8 CTL from genital herpes simplex lesions: recognition of viral tegument and immediate early proteins and lysis of infected cutaneous cells. J. Immunol. 2001, 166, 4049-4058.

23. Sharpe, M.; Lynch, D.; Topham, S.; Major, D.; Wood, J.; Loudon, P. Protection of mice from H5N1 influenza challenge by prophylactic DNA vaccination using particle mediated epidermal delivery. Vaccine 2007, 25, 6392-6398.

24. Vita, R.; Zarebski, L.; Greenbaum, J.A.; Emami, H.; Hoof, I.; Salimi, N.; Damle, R.; Sette, A.; Peters, B. The immune epitope database 2.0. Nucleic Acids Res. 2010, 38, D854-D862.

25. Rao, V.P.; Balasa, B.; Carayanniotis, G. Mapping of thyroglobulin epitopes: presentation of a 9 mer pathogenic peptide by different mouse MHC class II isotypes. Immunogenetics 1994, 40, 352-359.

26. Suri, A.; Lovitch, S.B.; Unanue, E.R. The wide diversity and complexity of peptides bound to class II MHC molecules. Curr. Opin. Immunol. 2006, 18, 70-77.

27. Wang, Y.D.; Sin, W.Y.; Xu, G.B.; Yang, H.H.; Wong, T.Y.; Pang, X.W.; He, X.Y.; Zhang, H.G.; Ng, J.N.; Cheng, C.S.; Yu, J.; Meng, L.; Yang, R.F.; Lai, S.T.; Guo, Z.H.; Xie, Y.; Chen, W.F. $\mathrm{T}$-cell epitopes in severe acute respiratory syndrome (SARS) coronavirus spike protein elicit a specific T-cell immune response in patients who recover from SARS. J. Virol. 2004, 78, 5612-5618.

28. Koelle, D.M.; Liu, Z.; McClurkan, C.M.; Topp, M.S.; Riddell, S.R.; Pamer, E.G.; Johnson, A.S.; Wald, A.; Corey, L. Expression of cutaneous lymphocyte-associated antigen by CD8(+) T cells specific for a skin-tropic virus. J. Clin. Invest. 2002, 110, 537-548.

29. Posavad, C.M.; Remington, M.; Mueller, D.E.; Zhao, L.; Magaret, A.S.; Wald, A.; Corey, L. Detailed Characterization of $\mathrm{T}$ Cell Responses to Herpes Simplex Virus-2 in Immune Seronegative Persons. J. Immunol. 2010, 184, 3250-3259.

30. Rowland-Jones, S.; Sutton, J.; Ariyoshi, K.; Dong, T.; Gotch, F.; McAdam, S.; Whitby, D.; Sabally, S.; Gallimore, A.; Corrah, T.; Takiguchi, M.; Schultz, T.; McMichael, A.; Whittle, H. HIV-specific cytotoxic T-cells in HIV-exposed but uninfected Gambian women. Nat. Med. 1995, $1,59-64$. 
31. Erickson, A.L.; Willberg, C.B.; McMahan, V.; Liu, A.; Buchbinder, S.P.; Grohskopf, L.A.; Grant, R.M.; Nixon, D.F. Potentially Exposed but Uninfected Individuals Produce Cytotoxic and Polyfunctional Human Immunodeficiency Virus Type 1-Specific CD8+ T-Cell Responses Which Can Be Defined to the Epitope Level. Clin. Vaccine Immunol. 2008, 15, 1745-1748.

32. Mo, A.; Musselli, C.; Chen, H.; Pappas, J.; Leclair, K.; Liu, A.; Chicz, R.M.; Truneh, A.; Monks, S.; Levey, D.L.; Srivastava, P.K. A heat shock protein based polyvalent vaccine targeting HSV-2: CD4(+) and CD8(+) cellular immunity and protective efficacy. Vaccine 2011, 29, 8530-8541.

33. Wald, A.; Koelle, D.M.; Fife, K.; Warren, T.; Leclair, K.; Chicz, R.M.; Monks, S.; Levey, D.L.; Musselli, C.; Srivastava, P.K. Safety and immunogenicity of long HSV-2 peptides complexed with rhHsc70 in HSV-2 seropositive persons. Vaccine 2011, 29, 8520-8529.

34. Loudon, P.T.; Yager, E.J.; Lynch, D.T.; Narendran, A.; Stagnar, C.; Franchini, A.M.; Fuller, J.T.; White, P.A.; Nyuandi, J.; Wiley, C.A.; Murphey-Corb, M.; Fuller, D.H. GM-CSF Increases Mucosal and Systemic Immunogenicity of an H1N1 Influenza DNA Vaccine Administered into the Epidermis of Non-Human Primates. PLoS One 2010, 5, e11021.

35. Jones, S.; Evans, K.; McElwaine-Johnn, H.; Sharpe, M.; Oxford, J.; Lambkin-Williams, R.; Mant, T.; Nolan, A.; Zambon, M.; Ellis, J.; Beadle, J.; Loudon, P.T. DNA vaccination protects against an influenza challenge in a double-blind randomised placebo-controlled phase $1 \mathrm{~b}$ clinical trial. Vaccine 2009, 27, 2506-2512.

36. Winstone, N.; Guimaraes-Walker, A.; Roberts, J.; Brown, D.; Loach, V.; Goonetilleke, N.; Hanke, T.; McMichael, A.J. Increased detection of proliferating, polyfunctional, HIV-1-specific T cells in DNA-modified vaccinia virus Ankara-vaccinated human volunteers by cultured IFN-gamma ELISPOT assay. Eur. J. Immunol. 2009, 39, 975-985.

37. Nakanishi, Y.; Lu, B.; Gerard, C.; Iwasaki, A. CD8+ T lymphocyte mobilization to virus-infected tissue requires CD4+ T-cell help. Nature 2009, 462, 510-513.

38. Oseroff, C.; Peters, B.; Pasquetto, V.; Moutaftsi, M.; Sidney, J.; Panchanathan, V.; Tscharke, D.C.; Maillere, B.; Grey, H.; Sette, A. Dissociation between Epitope Hierarchy and Immunoprevalence in CD8 Responses to Vaccinia Virus Western Reserve. J. Immunol. 2008, 180, 7193-7202.

39. Siddiqui, S.; Tarrab, E.; Lamarre, A.; Basta, S. Altered immunodominance hierarchies of CD8+ T cells in the spleen after infection at different sites is contingent on high virus inoculum. Microbes Infection 2010, 12, 324-330.

40. Tscharke, D.C.; Karupiah, G.; Zhou, J.; Palmore, T.; Irvine, K.R.; Haeryfar, S.M.M.; Williams, S.; Sidney, J.; Sette, A.; Bennink, J.R.; Yewdell, J.W. Identification of poxvirus CD8+ $\mathrm{T}$ cell determinants to enable rational design and characterization of smallpox vaccines. $J$. Exp. Med. 2005, 201, 95-104.

41. Chen, J.-L.; Dunbar, P.R.; Gileadi, U.; Jager, E.; Gnjatic, S.; Nagata, Y.; Stockert, E.; Panicali, D.L.; Chen, Y.-T.; Knuth, A.; Old, L.J.; Cerundolo, V. Identification of NY-ESO-1 Peptide Analogues Capable of Improved Stimulation of Tumor-Reactive CTL. J. Immunol. 2000, $165,948-955$. 
42. Morrison, J.; Elvin, J.; Latron, F.; Gotch, F.; Moots, R.; Strominger, J.L.; McMichael, A. Identification of the nonamer peptide from influenza A matrix protein and the role of pockets of HLA-A2 in its recognition by cytotoxic T lymphocytes. Eur. J. Immunol. 1992, 22, 903-907.

43. Betts, M.R.; Brenchley, J.M.; Price, D.A.; De Rosa, S.C.; Douek, D.C.; Roederer, M.; Koup, R.A. Sensitive and viable identification of antigen-specific CD8+ T cells by a flow cytometric assay for degranulation. J. Immunol. Meth. 2003, 281, 65-78.

44. Wolint, P.; Betts, M.R.; Koup, R.A.; Oxenius, A. Immediate Cytotoxicity But Not Degranulation Distinguishes Effector and Memory Subsets of CD8+ T Cells. J. Exp. Med. 2004, 199, 925-936.

45. Smith, C.L.; Dunbar, P.R.; Mirza, F.; Palmowski, M.J.; Shepherd, D.; Gilbert, S.C.; Coulie, P.; Schneider, J.; Hoffman, E.; Hawkins, R.; Harris, A.L.; Cerundolo, V. Recombinant modified vaccinia Ankara primes functionally activated CTL specific for a melanoma tumor antigen epitope in melanoma patients with a high risk of disease recurrence. Int. J. Cancer 2005, 113, 259-266.

46. Roberts, L.K.; Barr, L.J.; Fuller, D.H.; McMahon, C.W.; Leese, P.T.; Jones, S. Clinical safety and efficacy of a powdered Hepatitis B nucleic acid vaccine delivered to the epidermis by a commercial prototype device. Vaccine 2005, 23, 4867-4878.

(C) 2013 by the authors; licensee MDPI, Basel, Switzerland. This article is an open access article distributed under the terms and conditions of the Creative Commons Attribution license (http://creativecommons.org/licenses/by/3.0/). 